Article

\title{
A Semi-Analytic Model for Estimating Total Suspended Sediment Concentration in Turbid Coastal Waters of Northern Western Australia Using MODIS-Aqua $250 \mathrm{~m}$ Data
}

\author{
Passang Dorji *, Peter Fearns and Mark Broomhall \\ Remote Sensing and Satellite Research Group, Curtin University, GPO Box U1987, Perth, WA 6845, Australia; \\ P.Fearns@curtin.edu.au (P.F.); m.broomhall@bom.gov.au (M.B.) \\ * Correspondence: dorji.passang@postgrad.curtin.edu.au; Tel.: +61-8-9266-5267 \\ Academic Editors: Xiaofeng Li and Prasad S. Thenkabail \\ Received: 6 April 2016; Accepted: 24 June 2016; Published: 30 June 2016
}

\begin{abstract}
Knowledge of the concentration of total suspended sediment (TSS) in coastal waters is of significance to marine environmental monitoring agencies to determine the turbidity of water that serve as a proxy to estimate the availability of light at depth for benthic habitats. TSS models applicable to data collected by satellite sensors can be used to determine TSS with reasonable accuracy and of adequate spatial and temporal resolution to be of use for coastal water quality monitoring. Thus, a study is presented here where we develop a semi-analytic sediment model (SASM) applicable to any sensor with red and near infrared (NIR) bands. The calibration and validation of the SASM using bootstrap and cross-validation methods showed that the SASM applied to Moderate Resolution Imaging Spectroradiometer (MODIS)-Aqua band 1 data retrieved TSS with a root mean square error (RMSE) and mean averaged relative error (MARE) of $5.75 \mathrm{mg} / \mathrm{L}$ and $33.33 \%$ respectively. The application of the SASM over our study region using MODIS-Aqua band 1 data showed that the SASM can be used to monitor the on-going, post and pre-dredging activities and identify daily TSS anomalies that are caused by natural and anthropogenic processes in coastal waters of northern Western Australia.
\end{abstract}

Keywords: total suspended sediment; remote sensing; coastal waters; semi-analytic algorithm; MODIS

\section{Introduction}

The use of satellite remote sensing of coastal waters to derive their bio-geophysical properties provides marine scientists and managers with a relatively affordable alternative to in situ based sampling. Remote sensing has been used to map a wide array of coastal water's constituents, such as phytoplankton for biomass and primary production [1-4], coloured dissolved organic matter (CDOM) for its effect on benthic habitats [5-7], and total suspended sediments (TSS) concentration as a measure of water quality [8-12]. Many studies have been performed to derive TSS concentration via satellite remote sensing using different platforms: Sea-viewing Wide Field-of-view Sensor (SeaWiFS) [13,14], Landsat series [15-20], Medium Resolution Imaging Spectrometer (MERIS) [21-26], Moderate Resolution Imaging Spectroradiometer (MODIS) [9,11,25,27-30], "Système Pour l'Observation de la Terre" (SPOT) [31], and high resolution sensor IKONOS [32]. Most models are developed to estimate TSS concentration by directly relating the remotely sensed reflectance with in situ measurements of the TSS concentration using statistical analysis, linear and non-linear regression. These models may use a single spectral band [16,33-38] or combinations of different spectral bands [15,21,28,39-42] with regression analysis to predict the TSS concentration. Linear approximations from regression analysis 
are valid for relatively low TSS concentrations but as the TSS concentration increases the linearity weakens and the reflectance saturates at high TSS concentration [13,43]. The saturation of reflectance occurs at high TSS concentration because the increased water column scattering leads to a relative enhancement in absorption/attenuation of the backscattered light [44]. In such cases, a non-linear approximation such as a higher order polynomial or exponential function $[13,29,35,45]$ is used to relate the TSS concentration to reflectance. Combinations of different spectral bands in visible and near infrared (NIR) spectral regions have been used to estimate the TSS concentration in coastal waters that varied vastly in concentrations, from less than $11.0 \mathrm{mg} / \mathrm{L}$ [25,46-48] to very high, greater than $2000 \mathrm{mg} / \mathrm{L}[13,49,50]$. Spectral bands in the blue and green spectral regions with $[23,41,51,52]$ or without (Jiang and Liu 2011 as cited in [28,53]) the combinations of red or NIR bands are used by many researchers to explore the potential of TSS mapping using different band combinations. However, more recently, single band estimations of the TSS concentration using the red or NIR bands have been widely used in TSS algorithms because of the particulates dominance in total backscattering when compared with the optical response of other components in these regions of the electromagnetic spectrum.

Empirical methods are most often used to estimate TSS concentration because of their simplicity in development. However, the lack of a physical basis in empirical models limits their general applicability to other than a local area where the algorithm was developed and ones confidence in extrapolating the model to higher of lower concentration than those on which it was developed [54]. In recent decades, physical and semi-analytical models relating inherent optical properties (IOPs) of water to apparent optical properties (viz. irradiance reflectance just beneath the water surface) are used to estimate bio-geophysical parameters of interest [11,18,22,54-58]. A physical model, which is based on radiative transfer theory, requires that the in situ inherent optical properties of water, atmospheric conditions and several other factors are accurately known to enable the determination of TSS concentration [44]. Use of semi-analytical models that combine both physical foundations and statistical analyses provide a promising method to estimate TSS concentration with limited knowledge of the in situ optical properties of the water body $[57,59,60]$.

Semi-analytic TSS algorithms include model parameters that use in situ regional IOPs [54], averaged IOPs representative of wider geographical locations [60] or IOPs inverted from site specific satellite reflectance [61]. The site specific IOPs used in parameterizing these models are potentially the best for retrieving site-specific TSS. However, notwithstanding the inherent uncertainties and limitations of in situ IOP instruments, the acquisition of IOPs is also challenging due to financial, logistical and time factors for rapid assessment of TSS. The dependence of IOPs on site-specific water constituents limits the use of published IOPs from other areas as an alternative without compromising the quality of the derived TSS concentration. The IOPs obtained by inverting the site specific satellite reflectance are also not without limitations because the inverted IOPs are affected by not only the uncertainties of IOPs from inversion models but also uncertainties of the reflectance product from which the IOPs are derived. The study conducted by [62] to determine the uncertainties of IOPs derived from semi-analytic models quantified that $20 \%$ of derived absorption coefficients were outside the $90 \%$ confidence limit while for the backscattering coefficient $\sim 50 \%$ were outside the $90 \%$ confidence limit.

In this study, we proposed a semi-analytic sediment model (SASM) that had a basis in radiative transfer theory and was locally tuned to the regional waters of northern Western Australia for MODIS-Aqua band 1 to monitor TSS concentration in the region. The SASM was applied to the coastal waters of northern Western Australia using MODIS-Aqua $250 \mathrm{~m}$ data for mapping the TSS concentration in the region, which would serve as a baseline in future water quality monitoring of the region. 


\section{Materials and Methods}

\subsection{Study Site}

Onslow waters fall within the Pilbara Coast West (from Exmouth to Karratha) of Western Australian centred at $21^{\circ} 35^{\prime} 00^{\prime \prime} \mathrm{S}$ and longitude $115^{\circ} 05^{\prime} 00^{\prime \prime} \mathrm{E}$ (Figure 1 ) and experience an annual average temperature of $29.2^{\circ} \mathrm{C}$ and mean annual rainfall of $296 \mathrm{~mm}$ [63]. The discovery of the Wheatstone gas field off the coast of Onslow in 2004 has led to the construction of 25 million tonnes per year gas processing plants [64] with the dredging of a shipping access channel to the processing plants beginning from May 2013 till end of September 2013 in the location of the dredge area (DA) in Figure 1 [65]. The dredging operation was expected to generate 45 million $\mathrm{m}^{3}$ of dredge spoil [65], and the activity has some level of impact on the marine ecosystem in the region.

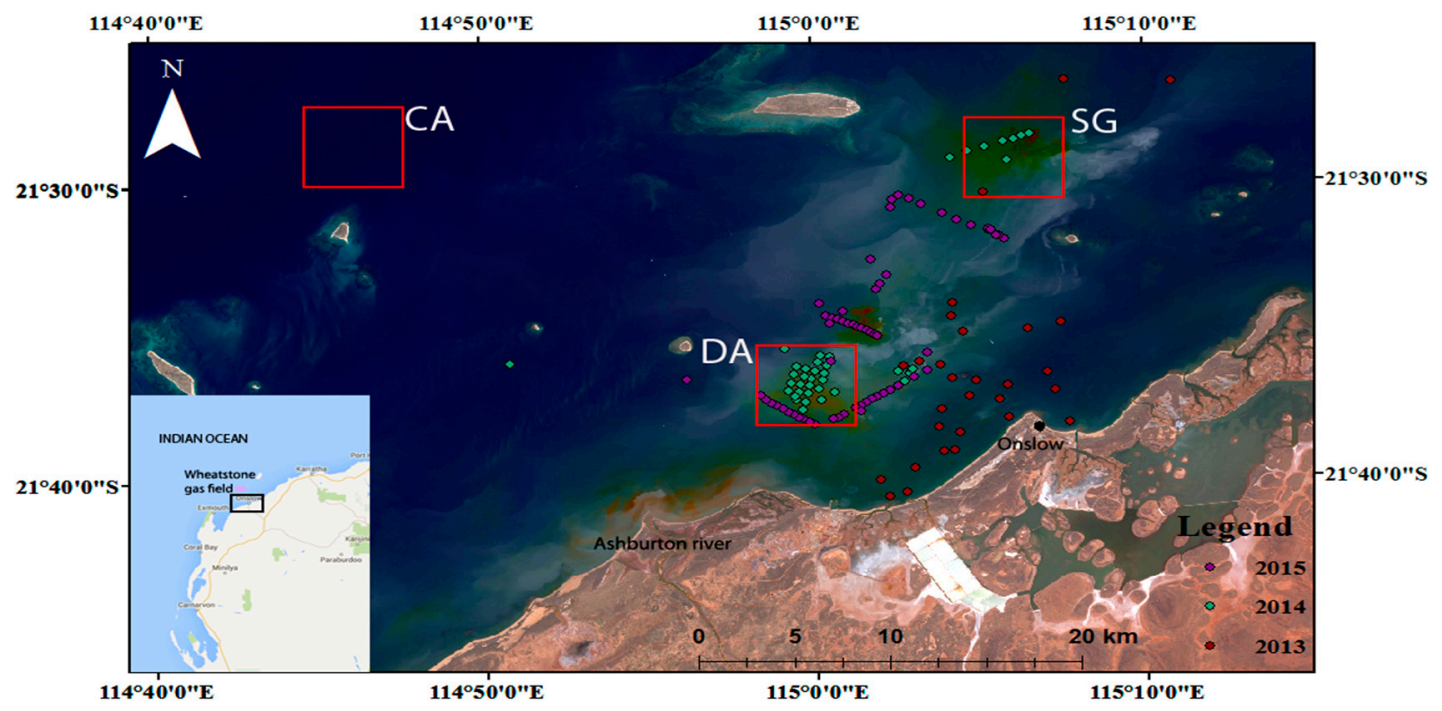

Figure 1. True colour $15 \mathrm{~m}$ pan sharpened Landsat OLI (Operational Land Imager) imagery showing study site and the location of the sampling stations. Red squares represent the location of dredge area (DA), spoil ground (SG), and clean area (CA) used in the temporal analysis. Red, purple and green filled circles are the locations of water sampling stations in 2013, 2014 and 2015 respectively.

\subsection{In Situ and Remote Sensing Data}

The satellite-based remote sensing data for this study were MODIS-Aqua data spanning the years 2013 to 2015, acquired as Level 1B data from the NASA LAADS web (http://ladsweb.nascom.nasa.gov/). The in situ data of reflectance samples was collected using a hyperspectral radiometer, the "Dynamic above-water radiance and irradiance collector" (DALEC) and simultaneously, water samples were gathered for TSS measurements. In total three field campaigns were carried out in the study site collecting a total of 130 water samples. First two field campaigns were carried out on board the RV Linnaeus, operated by the Commonwealth Scientific and Industrial Research Organisation (CSIRO) during October 2013 and June 2014. The third field campaign was carried out in July 2015 on the Australian Institute of Marine Science (AIMS) RV Solander (Figure 1).

\subsubsection{The DALEC Radiometer}

The DALEC, a hyperspectral radiometer developed by "In situ Marine Optics" is used routinely for autonomous ship-based measurement of remote sensing reflectance [66]. The DALEC takes coincident measurements of downwelling irradiance $\left(E_{\mathrm{d}}\right)$, upwelling radiance $\left(L_{\mathrm{u}}\right)$ and sky radiance $\left(L_{\text {sky }}\right)$ with each sensor collecting spectral information in 256 spectral bins ranging from $380 \mathrm{~nm}$ to $900 \mathrm{~nm}$. Measurement of radiance from the $L_{\mathrm{u}}$ and $L_{\mathrm{sky}}$ sensors and irradiance from the $E_{\mathrm{d}}$ sensor 
can be used to compute remote sensing reflectance $\left(R_{\mathrm{rs}}\right)$ using the ad hoc formula of Mobley [67], as shown by Equation (1),

$$
R_{r s}(\lambda)=\frac{L_{\mathrm{u}}(\lambda) \rho L_{\mathrm{sky}}(\lambda)}{E_{d}(\lambda)}
$$

where $\rho$ is a correction factor which is dependent on sky radiance, solar zenith angle, wind speed and the instrument's viewing angle [67]. The value of $\rho$ was set to 0.022 as prescribed by Mobley [67] for uniform sky conditions and wind speed less than $5 \mathrm{~m} \cdot \mathrm{s}^{-1}$. DALEC data were collected between 10:00 am and 3:00 pm local time when cloud cover was below 10\%, the wind speed less than $5 \mathrm{~m} \cdot \mathrm{s}^{-1}$ and the sea waves and swell were below $0.5 \mathrm{~m}$.

As recommended by Mobley [67], the DALEC's azimuthal viewing angle was maintained at $135^{\circ}$ relative to the solar direction and the viewing angles of the $L_{\mathfrak{u}}$ and $L_{\text {sky }}$ sensors were set at $40^{\circ}$ off nadir and zenith respectively to minimize the sun glint and instrument shading. The necessary adjustment to the orientation of the DALEC was carried out as and when the heading of the ship changed during the course of the measurements.

\subsubsection{DALEC Data Collection and Analysis}

The DALEC was mounted on the bow of the research vessel using a horizontal pole to a distance such that disturbance from the wake of the ship was avoided. The DALEC is capable of running continuously, and collecting individual spectra at integration times selected automatically in response to illumination conditions. On average DALEC was able to collect 11 reflectance spectrum per minute. The DALEC was operated whilst the boat was underway and also when "on station", with the on station periods lasting at least 5 min to allow collection of TSS samples.

Despite taking necessary steps discussed above as recommended by Mobley [67] to avoid specular reflection of sunlight from some wave facets for the reflectance measurements, still some spectra can be contaminated by the sun glint. These sun glint affected spectra are removed from the time series of data prior to subsequent analysis. After elimination of sun glint contaminated spectra there were at least 5 reflectance spectra per stations every minute. Typically, an average spectrum is derived from a set of measurements coinciding with the collection of the TSS sample. Analysis of the variation in reflectance spectra, by calculating the standard deviation for time periods of $\pm 1 \mathrm{~min}, \pm 3 \mathrm{~min}$, and $\pm 5 \mathrm{~min}$ from time when TSS sample was collected, showed that the standard deviation for each set of data was comparable. On average, we selected $\pm 3 \mathrm{~min}$ as the standard averaging period for all stations.

\subsubsection{Water Sample Collection and Analysis}

During the first two field trips we collected a minimum of two 1 litre sample bottles of water from 0.5-1 m depth at each station while the boat was stationary. For the third field trip, we collected water samples using an underway seawater sampling system on the AIMS RV Solander, which has a sea water intake system at a depth of $\sim 1.9 \mathrm{~m}$ below the ocean surface.

All the water samples collected where processed for TSS concentration using the gravimetric method within six hours from the time the water samples were collected. Whatman GF/F filters ( $47 \mathrm{~mm}$ diameter, nominal pore size $0.7 \mu \mathrm{m}$ ) were pre-prepared in the laboratory by rinsing each filter with $50 \mathrm{~mL}$ of distilled/deionized water followed by drying at $60{ }^{\circ} \mathrm{C}$ in an oven for over $12 \mathrm{~h}$. The water samples were filtered using low vacuum pressure and the filter flushed with $50 \mathrm{~mL}$ of deionized water to remove residual salt. The filtered TSS samples were stored in a cool dry place until being taken back to the laboratory where they were dried for at least $24 \mathrm{~h}$ at $60{ }^{\circ} \mathrm{C}$. The dried filters were then repeatedly measured until the measured weight was constant within the tolerance weight limit of $0.001 \mathrm{mg} / \mathrm{L}$.

Analysis of TSS samples collected during the third field trip showed that the TSS did not correlate with the reflectance measurements or other optical measurements. Collecting the water samples from a depth of $\sim 1.9 \mathrm{~m}$ might have resulted in the in situ TSS concentration being different from the actual expected value at the surface $(\sim 0.5-1.0 \mathrm{~m})$ if the water column is stratified. In fact, observations from 
acoustic instruments did often show strong stratification, with suspended sediment loads increasing with depth. Thus, data from the third field trip were excluded from the algorithm development or TSS product validation in this study with the exception of DALEC measurements of the remote sensing reflectance to be used in the validation of the atmospheric correction process because DALEC data on 6 July 2015 were acquired within 15 min from the MODIS-Aqua overpass. The details of water column stratification on the MODIS sensor at band 1 is discussed in Appendix A.

\subsubsection{Satellite Data Acquisition}

MODIS-Aqua level 1B images containing geo located at-aperture radiances for all 36 spectral bands were acquired from NASA LAADS web for the dates corresponding to all the field trips for the validation of the MODIS-Aqua derived TSS. The images were assessed for sun glint contamination and cloud cover over the study sites and found to be free of cloud and sun glint. In addition to the aforementioned MODIS-Aqua images, additionally 247 MODIS-Aqua images free of cloud and sun glint in the study site for the year 2013 coinciding with the dredge operation to construct access channels for a gas processing plant by Chevron Pty Ltd. (Perth, Austrilia) were also acquired for time series analysis. All MODIS-Aqua 1B images were processed for atmospheric correction, water pixel extraction for the validation, and spatial consideration for the temporal analysis.

\subsubsection{Atmospheric Correction}

For the atmospheric correction, the top of the atmosphere (TOA) radiance from the MODIS-Aqua Level 1B products were converted to atmospherically corrected, at-surface remote sensing reflectance using the multi-sensor Level 1 to Level 2 generator (12gen) function which can be run as a stand-alone program or accessed through the SeaDAS 7.2 interface [68]. Among many atmospheric correction algorithms available for data processing in SeaDAS we considered two, the standard atmospheric correction method for MODIS high resolution data SWIR [69], and the MUMM [70] atmospheric correction method, because previous studies [56,70-72] have demonstrated that these two atmospheric correction algorithms are effective for turbid coastal waters. The SWIR atmospheric algorithm estimates the aerosol reflectance using the $1240 \mathrm{~nm}$ and $2130 \mathrm{~nm}$ MODIS bands while the MUMM atmospheric correction is based on the spatial homogeneity of water-leaving radiances and aerosol ratios for the MODIS $748 \mathrm{~nm}$ and $869 \mathrm{~nm}$ bands [71].

Both the MODIS high resolution and MUMM atmospheric correction were applied to MODIS-Aqua Level 1B data for 6 July 2015 because all the DALEC $R_{\mathrm{rs}}$ data collected on 6 July 2015 were within 15 min of MODIS overpass time compared to in excess of at last 90 min on other sampling dates. A comparative analysis of $R_{\mathrm{rs}}$ data from the two atmospheric correction methods considered (results discussed in Section 3.2) showed that MUMM is better at retrieving $R_{\mathrm{rs}}$ when compared with the standard MODIS high resolution SWIR atmospheric correction method for our study site. All MODIS-Aqua data were subsequently processed with the MUMM atmospheric correction approach. However, analysis of the products showed that MUMM's default cloud screening band at $869 \mathrm{~nm}$ caused the turbid plumes to be flagged as clouds, thus we applied the $2130 \mathrm{~nm}$ band instead.

\subsubsection{Water Pixel Extraction and Analysis}

For water pixel extraction, we used the geographical location of the in situ TSS sampling stations that were within $\pm 30 \mathrm{~min}, \pm 60 \mathrm{~min}$ and $\pm 90 \mathrm{~min}$ from MODIS-Aqua overpass time. Herein, data are referred to as Aqua Validation Data (AVD) and followed by the suffix 30, 60 and 90 for data collected within $\pm 30 \mathrm{~min}, \pm 60 \mathrm{~min}$ and $\pm 90 \mathrm{~min}$ of MODIS-Aqua overpass respectively. For the AVD30, AVD60 and AVD90 there were 18, 28 and 45 match-up pairs between MODIS-Aqua derived TSS and in situ TSS respectively. TSS from each location at the validation sites were extracted using the SeaDAS pixel extraction tool for window sizes of a single pixel, $3 \times 3$ pixels, and $5 \times 5$ pixels to account for the pixel variability in the error analysis. 
For the selection of the location and the spatial extent in the MODIS derived TSS for performing the time series analysis, we focused on three different regions in the study site after careful analysis of the pan-sharped $15 \mathrm{~m}$ Landsat imagery to confirm appropriate locations to represent (1) clean area (CA); (2) dredge area (DA); and (3) spoil ground (SG). All three areas of interest were confined to a spatial extent of $25 \mathrm{~km}^{2}$ after visually examining the high spatial resolution Landsat images. The CA was selected away from the main dredging area and further off the coast, the DA was selected at a location coincident with dredging operations, and the SG was selected at a location where spoils from the dredge operations were dumped. MODIS-derived TSS concentrations corresponding to each location were extracted for MODIS-Aqua time series analysis. The spatial extent and the geographical locations of CA, DA and SG are shown in Figure 1.

\subsection{SASM Model Formulations}

The formulation of the SASM describes the relationship between TSS concentration and ocean reflectance, thus providing a means to estimate TSS concentration using remote sensing methods. The approach is based on general radiative transfer theory and the Quasi Analytic Algorithm of Lee, et al. [73].

\subsubsection{Reflectance Model}

Gordon, et al. [74] showed subsurface remote sensing reflectance $\left(r_{\mathrm{rs}}\right)$, is related to the total absorption coefficient, $a(\lambda)$, and total backscattering coefficient, $b_{\mathrm{b}}(\lambda)$, through:

$$
r_{\mathrm{rs}}(\lambda) \approx \sum_{i=1}^{2} g_{i}\left[\frac{b_{\mathrm{b}}(\lambda)}{a(\lambda)+b_{b}(\lambda)}\right]^{i}
$$

The coefficients $g_{\mathrm{i}}$ depend on solar angle, scattering phase function, bidirectional reflectance effects and water surface conditions. Gordon, et al. [74] gave $\mathrm{g}_{1}=0.0949$ and $\mathrm{g}_{2}=0.0794$ for case- 1 waters and Lee, et al. [59] demonstrated that $g_{1}=0.084$ and $g_{2}=0.17$ are more suitable for highly scattering coastal waters. In this study, we adopted the values of $g_{1}$ and $g_{2}$ provided by Lee, et al. [59].

The $R_{\mathrm{rs}}(\lambda)$ which are measured by above-water radiometer can relate to $r_{\mathrm{rs}}(\lambda)$ using the relationship from Lee, et al. [59] as shown in Equation (3).

$$
r_{\mathrm{rs}}(\lambda)=\frac{R_{\mathrm{rs}}(\lambda)}{\left(0.52+1.7 R_{\mathrm{rs}}(\lambda)\right)}
$$

The total absorption coefficient is expressed as the sum of absorption coefficients for pure sea water $\left(a_{\mathrm{w}}(\lambda)\right)$, particulate matter $\left(a_{\mathrm{p}}(\lambda)\right)$, phytoplankton pigments $\left(a_{\varphi}(\lambda)\right)$, and coloured dissolved organic matter $\left(a_{\mathrm{cdom}}(\lambda)\right)$.

$$
a(\lambda)=a_{\mathrm{p}}(\lambda)+\underbrace{a_{\mathrm{w}}(\lambda)+a_{\varphi}(\lambda)+a_{\mathrm{cdom}}(\lambda)}_{a_{\text {other }}}
$$

The total backscattering coefficient is expressed as the sum of backscattering coefficients for pure sea water $\left(b_{\mathrm{bw}}(\lambda)\right)$, particulates $\left(b_{\mathrm{bp}}(\lambda)\right)$, and phytoplankton pigments $\left(b_{\mathrm{b} \varphi}(\lambda)\right)$.

$$
b_{b}(\lambda)=b_{\mathrm{bw}}(\lambda)+b_{\mathrm{bp}}(\lambda)+b_{\mathrm{b} \varphi}(\lambda)
$$

Equation (2) representing the subsurface remote sensing reflectance as a function of the IOPs can be rewritten as a quadratic equation as follows:

$$
r_{\mathrm{rs}}(\lambda)=g_{1} x(\lambda)+g_{2} x^{2}(\lambda)
$$


where

$$
x(\lambda)=\frac{b_{\mathrm{b}}(\lambda)}{a(\lambda)+b_{\mathrm{b}}(\lambda)}
$$

\subsubsection{Inherent Optical Properties Model}

In the IOPs model we represent the ratio of $b_{\mathrm{b}}(\lambda)$ to $a(\lambda)$ as $\omega_{b}^{\prime}(\lambda)$ as follows:

$$
\omega_{b}^{\prime}(\lambda)=\frac{b_{\mathrm{b}}(\lambda)}{a(\lambda)}
$$

For the case of turbid water, we adopt the following assumptions:

- For high-scattering coastal waters, $b_{\mathrm{b}}(\lambda)$ is mainly due to the backscattering coefficient from particulate matter and water molecules, the backscattering coefficient contributions from other constituents are insignificant [75]. Further, in the red and NIR regions of the spectrum the scattering by water molecules becomes insignificant, thus we can make an assumption that total backscattering in the red and NIR regions is due to particulate matter only. Equation (5) can be approximated as:

$$
b_{\mathrm{b}}(\lambda) \approx b_{\mathrm{bp}}(\lambda)
$$

The assumption in Equation (9) can potentially be undermined for extreme concentrations of chlorophyll during phytoplankton blooms because in such cases, the backscattering from chlorophyll can be significant and cannot be ignored. HydroLight simulations show that even in the extreme case of high chlorophyll concentration $\left(10 \mathrm{mg} \cdot \mathrm{m}^{-3}\right)$ the backscattering contribution from chlorophyll constitute backscattering equivalent of TSS concentration of $3.4 \mathrm{mg} / \mathrm{L}$ and $3.6 \mathrm{mg} / \mathrm{L}$ at MODIS band 1 and 2 respectively. The backscattering contribution from pure water is calculated to be $\sim 20 \%$ and $\sim 9 \%$ of backscattering coefficient of MODIS band 1 and band 2 respectively than the TSS backscattering contribution even at TSS concentration of $0.2 \mathrm{mg} / \mathrm{L}$. The coastal waters in Western Australia typically shows a seasonal cycle in chlorophyll with average low values of $0.24 \mathrm{mg} \cdot \mathrm{m}^{-3}$ during summer and peaks in June with average values of $0.69 \mathrm{mg} \cdot \mathrm{m}^{-3}$ [76]. Considering the concentration of chlorophyll is typically less than $1 \mathrm{mg} \cdot \mathrm{m}^{-3}$ and its backscattering effect minimal even during the peak seasons in coastal waters of Western Australia, we can assume Equation (9) is valid for both MODIS band 1 and band 2. An added bonus that the aforementioned MODIS bands are both capable of is a $250 \mathrm{~m}$ spatial resolution.

- Following $[77,78]$ we can assume the particulate backscattering coefficient $\left(b_{\mathrm{bp}}(\lambda)\right)$ and absorption coefficient $\left(a_{\mathrm{p}}(\lambda)\right)$ to be proportional to TSS concentration, via appropriate constants- the specific particulate backscattering coefficient $\left(b_{\mathrm{bp}}{ }^{*}(\lambda)\right)$ and specific particulate absorption coefficients $\left(a_{\mathrm{p}}^{*}(\lambda)\right)$.

$$
\begin{gathered}
b_{\mathrm{bp}}(\lambda)=b_{\mathrm{bp}}{ }^{*}(\lambda) \times \text { TSS } \\
a_{\mathrm{p}}(\lambda)=a_{\mathrm{p}}{ }^{*}(\lambda) \times \text { TSS }
\end{gathered}
$$

Taking into account the aforementioned assumptions, we can formulate Equation (8) into

$$
\operatorname{TSS}(\lambda)=\frac{C_{1}(\lambda) \omega_{b}^{\prime}(\lambda)}{1-C_{2}(\lambda) \omega_{b}^{\prime}(\lambda)}
$$

where $C_{1}(\lambda)=a_{\text {other }}(\lambda) / b_{\mathrm{bp}}{ }^{*}(\lambda)$ and $C_{2}(\lambda)=a_{\mathrm{p}}{ }^{*}(\lambda) / b_{\mathrm{bp}}{ }^{*}(\lambda)$.

Essentially, Equation (12) is equivalent to Equation (5) of Nechad, Ruddick and Park [60]. However, the difference between the two models lies in the approximation of $r_{\mathrm{rs}}(\lambda)$ where we use the second order approximation of Gordon, et al. [74] and Nechad, Ruddick and Park [60] make use of the first order approximation of $r_{\mathrm{rs}}(\lambda)$ from [74]. The difference in $r_{\mathrm{rs}}(\lambda)$ between Nechad, Ruddick and Park [60] 
and the SASM model stems from the computation of $\omega_{b}^{\prime}(\lambda)$ by each individual model. The details of reflectance models comparison between Nechad, Ruddick and Park [60] and SASM is presented in Supplementary Material.

\subsubsection{Consolidation of Reflectance and Inherent Optical Properties Model}

Equation (7) can be established in terms of $\omega_{b}^{\prime}(\lambda)$ using the relationship from Equation (8) as follows:

$$
x(\lambda)=\frac{\omega_{b}^{\prime}(\lambda)}{1+\omega_{b}^{\prime}(\lambda)} \quad \text { or } \quad \omega_{b}^{\prime}(\lambda)=\frac{x(\lambda)}{1-x(\lambda)}
$$

Substituting Equation (13) into Equation (12) gives:

$$
\operatorname{TSS}(\lambda)=\frac{C_{1}(\lambda)\left(\frac{x(\lambda)}{1-x(\lambda)}\right)}{1-C_{2}(\lambda)\left(\frac{x(\lambda)}{1-x(\lambda)}\right)}
$$

where $x(\lambda)$ is the positive root of the solution of the quadratic function shown as Equation (6), which is as follows:

$$
x(\lambda)=\frac{-g_{1}+\sqrt{\left(g_{1}\right)^{2}+4 g_{2} r_{r s}(\lambda)}}{2 g_{2}}
$$

The constants $C_{1}(\lambda)$ and $C_{2}(\lambda)$ in Equation (14) will be derived using regression analysis between in situ TSS measurements and $x(\lambda)$.

\subsection{Conversion of DALEC Remote Sensing Reflectance to Sub-Surface Remote Sensing Reflectance}

Fact that DALEC and MODIS have different spectral resolutions and the SASM uses $r_{\text {rs }}$ in its model, it is necessary to convert DALEC $R_{\mathrm{rs}}$ to MODIS equivalent below-water surface $r_{\mathrm{rs}}$. Thus, in situ DALEC-measured $R_{\mathrm{rs}}$ were convolved to MODIS band 1 (B1) and band 2 (B2) equivalent $R_{\mathrm{rs}}$ using spectral response functions of the MODIS-Aqua following the method described in [60]. The MODIS B1 and B2 equivalent $R_{\mathrm{rs}}$ were then converted to $r_{\mathrm{rs}}$ using the relationship defined in Equation (3). Herein, in situ DALEC $R_{\mathrm{rs}}$ convolved to MODIS band equivalent $R_{\mathrm{rs}}$ and converted to sub-surface remote sensing reflectance will be referred as $r_{\mathrm{rs}}(\mathrm{B} 1)$ and $r_{\mathrm{rs}}(\mathrm{B} 2)$ for MODIS band 1 and band 2 respectively.

\subsection{Regional Empirical Model}

Many regional algorithms that are used in estimating the TSS concentration from remote sensing image-derived reflectance or in situ reflectance use either linear or exponential models [79]. To compare the performance of the SASM with empirical models the simple form of linear and exponential models were selected as represented by Equations (16) and (17) respectively.

$$
\begin{aligned}
& \operatorname{TSS}(\lambda)=a x(\lambda)+b \\
& \operatorname{TSS}(\lambda)=a e^{b x(\lambda)}+c
\end{aligned}
$$

where $x$ is $r_{\mathrm{rs}}(\mathrm{B} 1)$ and $r_{\mathrm{rs}}(\mathrm{B} 2)$ and various combinations of the two bands and $a, b$, and $c$ are coefficients derived from regression analysis between TSS and $x$.

\subsection{Model Calibration and Model Uncertainty Estimates}

To calibrate the SASM and empirical models in Equations (14), (16), and (17) we used TSS and $r_{\mathrm{rs}}(\mathrm{B} 1)$ and $r_{\mathrm{rs}}$ (B2) and various combinations of the two bands from the data of the first two field trips. From the 69 TSS samples collected during the first two field campaigns only 48 stations afforded the appropriate match-up pair with $R_{\mathrm{rs}}$ data collected by the DALEC. For all TSS and $R_{\mathrm{rs}}$ match-up 
pairs, the TSS concentrations varied from a minimum of $2.4 \mathrm{mg} / \mathrm{L}$ to a maximum of $69.6 \mathrm{mg} / \mathrm{L}$ and mean of $9.89 \mathrm{mg} / \mathrm{L}$. In calibrating a model, it is desirable to have separate data sets for model calibration and testing collected independently of each other. However, due to the limitation of only acquiring 48 match-up pairs, we decided to use all 48 pairs for model calibration and validate using the leave-one-out cross-validation (LOOCV) procedure of Stone [80]. The LOOCV method is a commonly used statistical method in small sample size to allow for whole samples to be used in training and validations [81]. In this procedure, one pair of data is left as a validation data set and the remaining data are used in calibrating the model. This procedure is repeatedly executed excluding the pair that has been picked in previous validations and recalibrated using the new remaining data until all 48 pairs are validated.

Using all 48 match-up pairs the SASM in Equation (14) and empirical models in Equations (16) and (17) were calibrated. From the results discussed in Section 3.2, the different bands or their combinations were not at par in retrieving TSS when compared with the MODIS-Aqua band 1, thus we selected MODIS-Aqua band 1 for this study. Finally, all three calibrated models from Equations (14), (16), and (17) are presented below for MODIS-Aqua band 1.

$$
\begin{gathered}
\operatorname{TSS}(B 1)=\frac{23.47 \times\left(\frac{x(B 1)}{1-x(B 1)}\right)}{1-0.69 \times\left(\frac{x(B 1)}{1-x(B 1)}\right)},\left(\mathrm{R}^{2}=0.85\right) \\
\operatorname{TSS}(B 1)=612.72 \times r_{\mathrm{rs}}(B 1)-4.83,\left(\mathrm{R}^{2}=0.85\right) \\
\operatorname{TSS}(B 1)=2.41 \times \exp \left[40.12 \times r_{\mathrm{rs}}(B 1)\right]+0.89,\left(\mathrm{R}^{2}=0.85\right)
\end{gathered}
$$

The LOOCV method provides overall model accuracy but does not produce assessment of uncertainty in the results derived by the model [81]. The bootstrap method of Efron [82] as discussed in [81] provides a means to generate the confidence in models as a result of uncertain determination of model parameters, uncertainties in in situ measurements, and assumptions in the model formulations [81]. Following Efron [82], 1000 sets of data were generated using re-sampling via a re-substitution method, and $65 \%$ confidence limits and upper and lower bound of the derived TSS products were generated for all three models considered. The $65 \%$ confidence interval was obtained by the percentile method by taking the upper and lower $17.5 \%$ (the $17.5 \%$ and $82.5 \%$ quantiles) of the results from the bootstrap distribution.

\subsection{Accuracy Assessment for Model Performance}

The accuracy assessment was performed by comparing model-derived and in situ measurements with Root Mean Square Error (RMSE), the correlation coefficient $(R)$, and Mean Absolute Relative Error (MARE), which are defined in Equations (21)-(23).

$$
\begin{gathered}
\text { RMSE }=\sqrt{\frac{\sum_{i=1}^{n}\left(x_{i}-y_{i}\right)^{2}}{n}} \\
r=\frac{n \sum x_{i} y_{i} \sum x_{i} \sum y_{i}}{\sqrt{n \sum x_{i}^{2}\left(\sum x_{i}\right)^{2}} \sqrt{n \sum y_{i}^{2}\left(\sum y_{i}\right)^{2}}} \\
\text { MARE }=\frac{\sum_{i=1}^{n}\left|\left(x_{i}-y_{i}\right) / y_{i}\right|}{n} \times 100 \%
\end{gathered}
$$

where $n$ is the total number of samples, $x_{i}$ is the model-derived TSS and $y_{i}$ is the measured TSS. 


\section{Results and Discussion}

\subsection{Spectral Characterization of Field Spectral Measurements}

The DALEC measured spectral reflectance signatures for different concentrations of TSS show that in the blue region of the spectrum (400-495 nm) there is little distinct separation between $R_{\mathrm{rs}}$ spectra for low and high TSS concentrations (Figure 2). In the green (495-570 nm) and the yellow (570-590 nm) spectral regions there are general trends in the increment of the magnitude of $R_{\mathrm{rs}}$ with increases in TSS concentration. In addition, there is a tendency for the wavelength of maximum $R_{\mathrm{rs}}$ to increase with increasing TSS concentration, from about $570 \mathrm{~nm}$ at $3 \mathrm{mg} / \mathrm{L}$ to $590 \mathrm{~nm}$ at $69.6 \mathrm{mg} / \mathrm{L}$. For the red spectral region $(620-750 \mathrm{~nm})$, there is a distinct increment of the magnitude in $R_{\mathrm{rs}}$ spectra with increase in TSS concentration. For the case of the NIR region $(>750 \mathrm{~nm})$ there is no clear difference among $R_{\mathrm{rs}}$ spectra for TSS less than $13 \mathrm{mg} / \mathrm{L}$, but for higher TSS there is a distinct increment in magnitude of $R_{\mathrm{rs}}$ with the NIR $R_{\text {rs }}$ exhibiting an increasingly more distinct peak at $\sim 810 \mathrm{~nm}$.

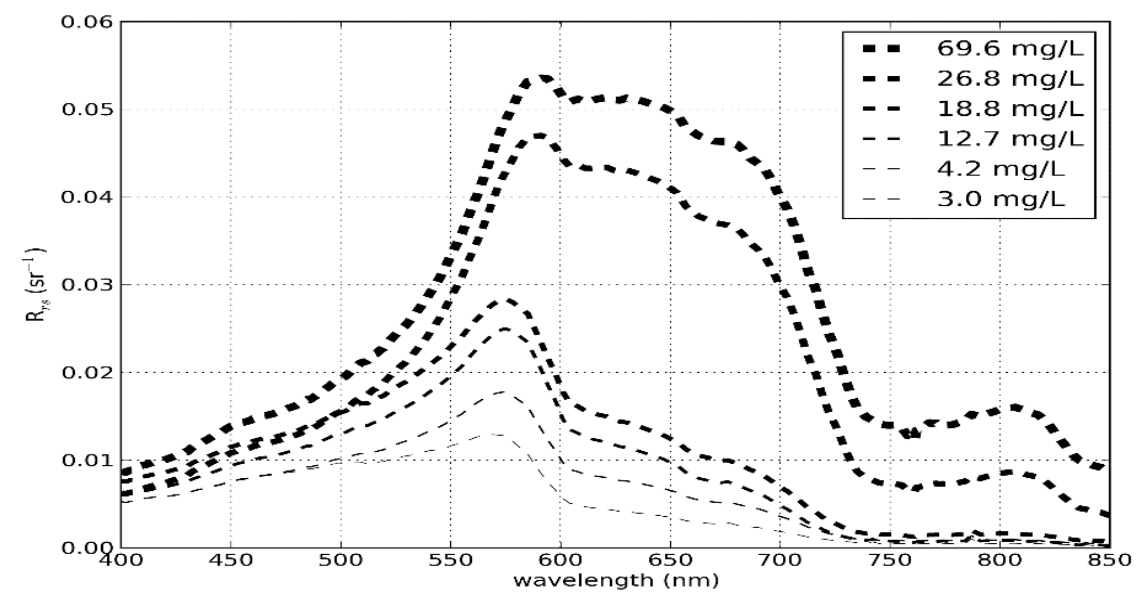

Figure 2. In situ DALEC spectral reflectance plots for different ranges of TSS concentration.

The selection of the red band and NIR bands for SASM are in agreement with [61] in considering band's responsiveness to TSS concentration in establishing a good retrieval model. In our spectral data, the reflectance at the red and NIR bands responds well with TSS concentration, as shown by the distinct increase in the magnitude of red band reflectance with increase in TSS concentration for all TSS concentrations, while the NIR band shows distinct increments for TSS concentrations greater than $13 \mathrm{mg} / \mathrm{L}$. The correlation coefficients $(r)$ between $R_{\mathrm{rs}}$ and TSS at the blue, green, red, and NIR regions of the spectrum were $0.66,0.42,0.84$, and 0.77 respectively, indicating the presence of a strong linear relationship between reflectance and TSS at red and NIR wavelengths.

\subsection{SASM Calibration and Validation}

The validation of the results for $r_{\mathrm{rs}}(\mathrm{B} 1)$ and $r_{\mathrm{rs}}(\mathrm{B} 2)$ and various band combination results obtained from the LOOCV method are shown in Table 1 . The results in Table 1 show that $r_{\mathrm{rs}}(\mathrm{B} 1)$ alone has better results than $r_{\mathrm{rs}}(\mathrm{B} 2)$ or combinations of the two bands. The poor performance result for $r_{\mathrm{rs}}(\mathrm{B} 2)$ may be because most of the available TSS measurements in our data set were lower. At low TSS concentrations and in the NIR wavelengths where the reflectance measurements are relatively low, results may be better modelled with a simple linear model which works well in low TSS concentrations [27,47]. However, in the waters with higher TSS concentrations and spectral regions where reflectance are high, the reflectance are not linearly related to the TSS concentration [52] so a different approach than a simple linear regression has to be taken. Thus, applying the SASM in MODIS band 1 to a region with low TSS concentration can avoid the lower reflectance issues in MODIS band 2 and also the SASM can 
address the problem of non-linearity between TSS and reflectance when using a simple linear model for higher TSS concentrations.

Table 1. Validation results from the LOOCV results for the SASM for MODIS-Aqua band 1, band 2 and their combinations.

\begin{tabular}{ccccc}
\hline Bands & $\boldsymbol{r}_{\mathrm{rs}}(\mathrm{B} 1)$ & $\boldsymbol{r}_{\mathbf{r s}}(\mathrm{B} 2)$ & $\boldsymbol{r}_{\mathbf{r s}}(\mathrm{B} 2 / \mathrm{B} 1)$ & $\left.\boldsymbol{r}_{\mathrm{rs}}(\mathbf{B} 1+\mathbf{B} 2) / \mathbf{2}\right)$ \\
\hline RMSE $(\mathrm{mg} / \mathrm{L})$ & 5.75 & 28.66 & 15.95 & 6.32 \\
MARE $(\%)$ & 33.33 & 82.90 & 102.78 & 38.52 \\
$r$ & 0.89 & -0.51 & 0.08 & 0.86 \\
\hline
\end{tabular}

The results of the SASM uncertainty obtained using the bootstrap method discussed in Section 2.6 is presented in Figure 3. The upper and lower bounds in Figure 3, shown by the grey shading represent the highest and the lowest TSS values obtained in the bootstrap results. The upper and lower bounds simply express the model uncertainty in deriving TSS concentration because of uncertainty in estimating model parameters from in situ data. The $65 \%$ confidence limit represented by dashed lines in Figure 3 defines a narrow band and closely follows the model curve indicating that the TSS retrieved by the SASM is closer to the expected TSS from the SASM. In Figure 3, the uncertainty estimates defined by the $65 \%$ confidence limits and upper and lower bounds are smaller at the lower concentration end of the curve and wider at the middle and upper part of the concentration curve. The smaller uncertainty at low TSS concentration is due to the availability of larger numbers of match-up ( $R_{\mathrm{rs}}$ and TSS) pairs while the higher uncertainty at high TSS is due to the limited number of match-up pairs. The future endeavour in collecting in situ TSS and $R_{\mathrm{rs}}$ should be focused on collection of more match-up pair that are evenly distributed throughout the range of different TSS concentrations.

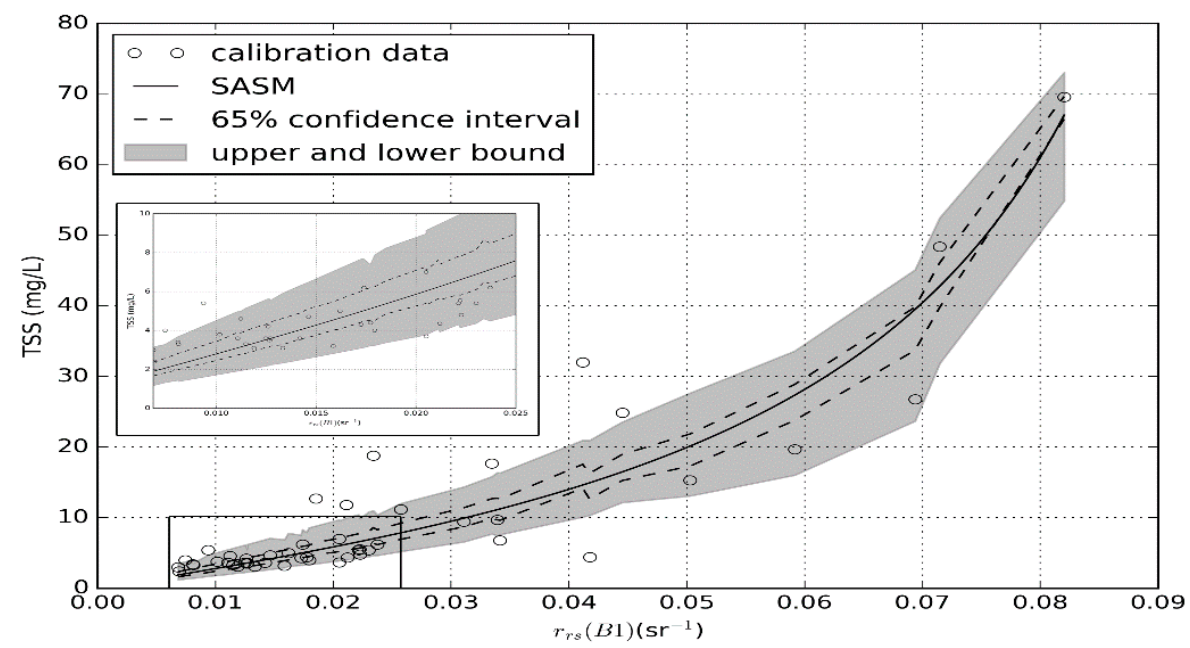

Figure 3. The SASM curve for $r_{\mathrm{rs}}(\mathrm{B} 1)$ (Equation (18)) is shown by the solid line. The in situ data points are shown by open circles. The $65 \%$ confidence limits obtained through the bootstrap method are shown by dashed lines. The greyed region represents the upper and lower bound for 1000 bootstrap runs.

\subsection{SASM Comparison with Empirical Models}

The accuracy assessment results for the SASM, the linear, and the exponential models obtained through the LOOCV process described in Section 2.6 are presented in Table 2. The results show that the SASM and the exponential models perform relatively better than the simple linear model in all three accuracy assessment categories. The comparison between the SASM and the exponential model are quite similar, however the SASM performs marginally better than the exponential model in all three assessment categories. Figure 4 shows TSS values derived from each model using the LOOCV 
method with respect to the in situ TSS values. Assessment of Figure 4 shows that all three models underestimate TSS when compared with in situ TSS for TSS greater than $30 \mathrm{mg} / \mathrm{L}$. We can speculate that underestimation is due to our calibration data set having more low TSS values, $75 \%$ of in situ TSS data collected were less than $10 \mathrm{mg} / \mathrm{L}$. Further, in the region where TSS were less than $30 \mathrm{mg} / \mathrm{L}$ there is no clear case supporting which model estimated TSS values better considering the large spread in the model-derived TSS by all three models.

Table 2. Results for the SASM, linear and exponential models for MODIS-Aqua band 1.

\begin{tabular}{cccc}
\hline Model & MARE (\%) & RMSE (mg/L) & $\boldsymbol{r}$ \\
\hline SASM & 33.33 & 5.75 & 0.89 \\
Linear & 59.17 & 7.39 & 0.80 \\
Exponential & 39.29 & 6.16 & 0.87 \\
\hline
\end{tabular}

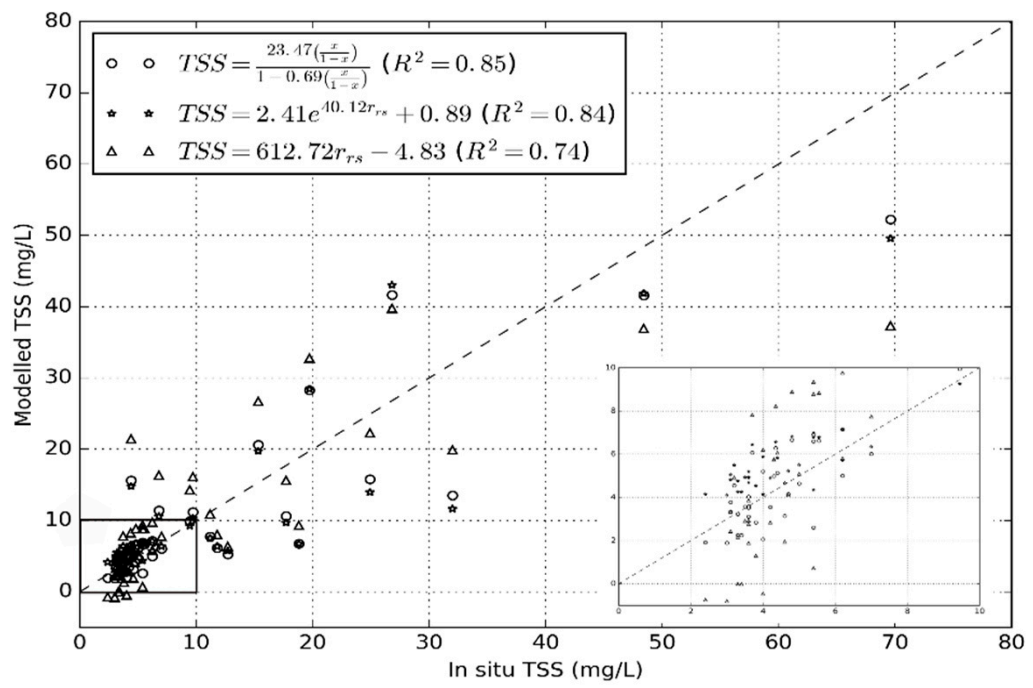

Figure 4. Validation results using the LOOCV method for the three models. The box at the bottom right is a blow out of the TSS $<10 \mathrm{mg} / \mathrm{L}$ and the dashed line is 1:1 line.

The results of model uncertainty defined by the upper, lower, and $65 \%$ confidence limits generated by the bootstrap method discussed in Section 2.6 are presented in Figure 5a,b for the linear and exponential models respectively. In addition to the confidence interval and the extreme bounds of each model, the relative errors (RE) for the lowest, median, and the largest TSS concentrations from the bootstrap distribution are also presented in Table 3 for the SASM, linear, and exponential models. The median value of the bootstrap results was used because of the random re-sampling procedure employed in the bootstrap methods results of extreme cases (possibly outliers) that affects the mean of whole distributions. The median RE value for all three models are similar to the MARE from the LOOCV method (shown in Table 2) which agrees with the results from the bootstrap method.

Table 3. Absolute relative error for the SASM, linear and exponential models derived from the bootstrap distribution of the TSS results.

\begin{tabular}{cccc}
\hline Model & Lowest RE (\%) & Median RE (\%) & Largest RE (\%) \\
\hline SASM & 1.20 & 30.93 & 228.15 \\
Linear & 2.20 & 53.64 & 349.90 \\
Exponential & 1.03 & 38.39 & 195.55 \\
\hline
\end{tabular}




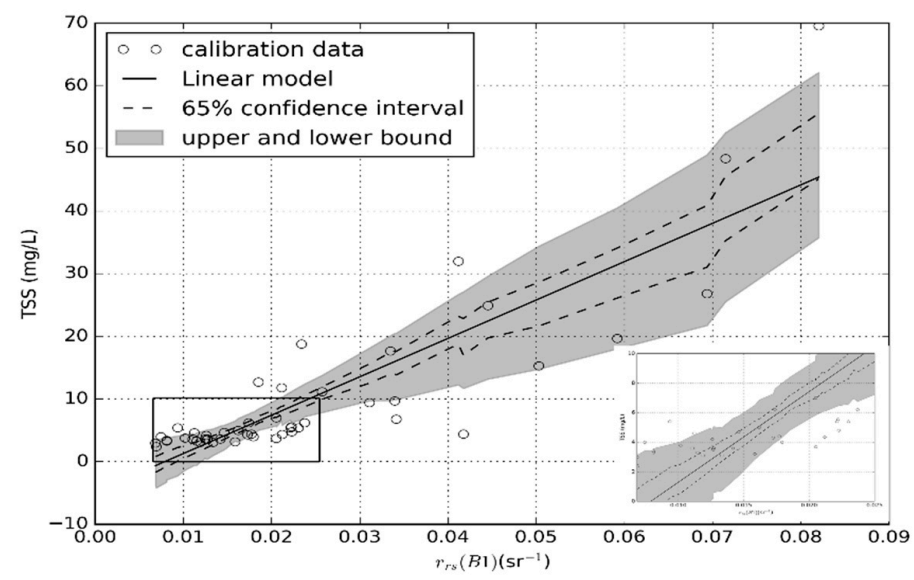

(a)

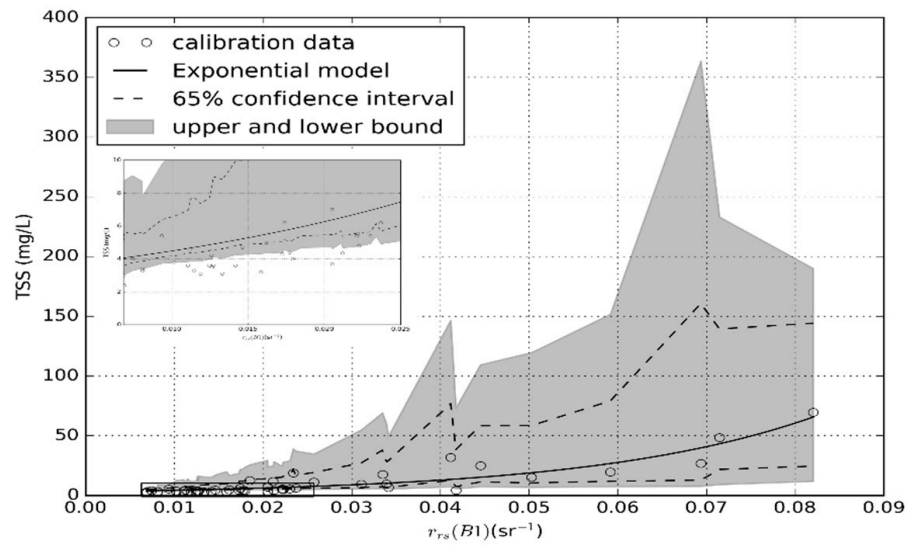

(b)

Figure 5. The empirical model curve for $r_{\mathrm{rs}}$ (B1) is shown by the solid line, in situ data points shown by open circles for both (a) the linear model and (b) the exponential model. In both the figures the $65 \%$ confidence limit obtained through the bootstrap method are shown by dashed lines. The greyed region represents the upper and lower bound for 1000 bootstrap runs. The upper and lower bound for exponential model has been limited to $95 \%$ CI because few high values of TSS were in excess of several thousand $\mathrm{mg} / \mathrm{L}$. The box at the bottom right in (a) and middle left (b) is a blow out of the TSS $<10 \mathrm{mg} / \mathrm{L}$ and $r_{\mathrm{rs}}(\mathrm{B} 1)<0.025 \mathrm{sr}^{-1}$.

From the results in Table 3 we observe that the lowest and largest RE is slightly better for the exponential model when compared with the SASM, but the mean RE is better for the SASM when compared with the exponential. The RE results of the linear model are all lower than the SASM and exponential model in all three categories of RE results. The bootstrap results of RE indicate slightly better performance for the exponential model. However, on considering the $65 \%$ confidence interval and upper and lower bounds of the bootstrap results in Figures 3 and 5 we observe that the SASM has a smaller $65 \%$ confidence interval and significantly smaller upper and lower bounds when compared with the exponential model.

Considering the retrieval error of TSS concentrations from MODIS algorithms is in the range of $\sim 18.0 \%$ to $\sim 61 \%$ for many studies conducted in the last decade, all three models looks feasible in estimating the TSS concentrations in the coastal waters of northern Western Australia. However, we must exercise caution when using any model, particularly when extending the application beyond the limits of the calibration data. A simple linear regression model depends on the linearity between TSS concentration and reflectance, which is observed to weaken as the turbidity of the water increases [52]. Without the proper calibration data for lower reflectance values, the linear model starts to yield negative 
TSS values at $R_{\mathrm{rs}}$ of $\sim 0.0042 \mathrm{sr}^{-1}$ in MODIS band 1 and underestimates TSS at higher $R_{\mathrm{rs}}$ values, as shown in Figure 5a. The exponential model gives closer values to the SASM than a simple linear model. Similar result between the SASM and exponential model might be because the non-linear relationship of reflectance and TSS concentration given by bio-optical models closely approximates the exponential curve [57]. However, we must caution using the exponential model within proper calibration data because for even zero $R_{\mathrm{rs}}$ the exponential model in our study gives minimum value of $3.308 \mathrm{mg} / \mathrm{L}$ for and over estimates TSS at higher $R_{\mathrm{rs}}$ values. In reality, even with the zero contributions from the constituents in the water there is still backscattering from water molecules, which when modelled using HydroLight gives $R_{\mathrm{rs}}$ of $\sim 0.000085 \mathrm{sr}^{-1}$ in MODIS band 1 for no contributions from in-water constituents. At this $R_{\mathrm{rs}}$ value the SASM, linear and exponential models give TSS of $0.002 \mathrm{mg} / \mathrm{L}$, $-4.778 \mathrm{mg} / \mathrm{L}$, and $3.308 \mathrm{mg} / \mathrm{L}$ respectively. In real world applications, the values provided by the linear and exponential models are not theoretically sensible whereas those TSS values provided by the SASM are closer to the values we would expect for near zero reflectance.

Considering the results from the LOOCV and bootstrap methods, the SASM is more suitable for the application of deriving TSS concentration using MODIS band 1 in coastal waters of northern Western Australia. However, when applied to sensors other than MODIS the SASM model would need to be recalibrated for that sensor. The collection of hyperspectral $R_{\mathrm{rs}}$ measurements using the DALEC and knowledge of the sensor band response functions makes this possible. We also have to be mindful that the error in TSS concentration is also impacted by factors such as atmospheric correction and sensor calibration, where a $5 \%$ error in radiance at-sensor results in 50 percent error in $R_{\mathrm{rs}}$ [23].

\subsection{Application to MODIS Imagery}

\subsubsection{Atmospheric Correction}

The difference between the standard MODIS high resolution SWIR and MUMM atmospheric correction methods was significant, as shown in Figure 6 for 6 July $2015 R_{\mathrm{rs}}$ data. The default MODIS 12gen atmospheric correction method for high resolution MODIS imagery underestimated $R_{\mathrm{rs}}$ on average by $39.2 \%$ while MUMM underestimated by only $5 \%$ in MODIS band 1 when compared with DALEC $R_{\mathrm{rs}}$.

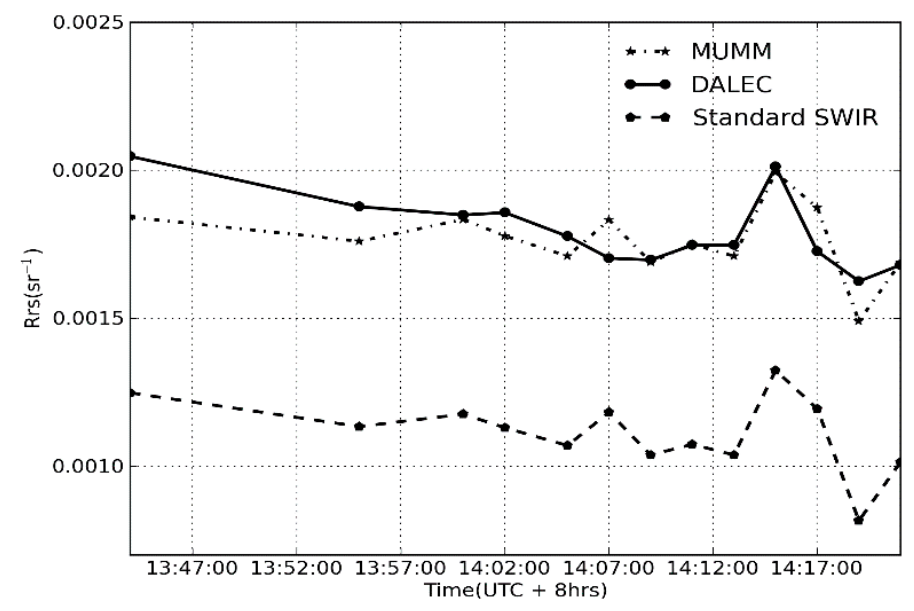

Figure 6. $R_{\mathrm{rs}}(\mathrm{B} 1)$ from the standard atmospheric correction method in SeaDAS SWIR and the MUMM atmospheric correction method in comparison with DALEC measurements for 6 July 2015.

The analysis of the MODIS-Aqua band 1 data corresponding to AVD30, AVD60, and AVD90 to estimate the error in reflectance derived from the satellite resulted in AVD30 with the least error in satellite derived reflectance with MARE of $9.7 \%$ while the highest is for AVD90 with $27.58 \%$, and AVD60 with MARE of $21.99 \%$. The correlation coefficients between DALEC $R_{\mathrm{rs}}$ and MUMM derived 
$R_{\text {rs }}$ were $0.98,0.86$, and 0.67 for AVD30, AVD60 and AVD90 respectively. Analysis of these results shows that as time the difference between satellite sensors and DALEC measurement decreases the difference between DALEC measured $R_{\mathrm{rs}}$ and MODIS $R_{\mathrm{rs}}$ also decreases. These results support the view amongst the remote sensing community that comparison between satellite sensor and in situ measurement can be improved by narrowing the time difference between the two. For this study, we used respective error for each AVD to account for the atmospheric correction error in subsequent analysis of the results in estimation of the TSS concentration.

\subsubsection{MODIS-Aqua Validation}

In order to consider the validation of the SASM results against the in situ TSS data, we have considered the contribution of two sources of error on the retrieval of TSS concentrations from MODIS-Aqua reflectance, namely the errors in the calibration of model parameters and errors arising from atmospheric correction. Notwithstanding the errors from other sources specifically, such as satellite sensor calibration, time difference between satellite image acquisition, and errors in in situ TSS measurements, the total error for AVD30, AVD60, and AVD90 were 43.03\%, 55.32\%, and $60.91 \%$ respectively. The total error is obtained from the following sources: MARE of $33.33 \%$ as a model error from the SASM in MODIS band 1 plus respective error for the AVD30, AVD60 and AVD90 from the atmospheric correction process presented in Section 3.4.1.

The validation of the TSS concentration derived using SASM in MODIS-Aqua band 1 shows that AVD30 has the better performance with a MARE of 35.39\% while AVD60 and AVD90 had MARE of $94.38 \%$ and $78.62 \%$ respectively. As the duration between satellites overpass timing and measurement increases, the mismatch between the in situ and satellite derived TSS also increases depending on the spatial variability and water dynamics influenced by ocean currents and wind. To account for the source of error of TSS due to time difference between satellite image acquisition and in situ measurement, we calculated the average TSS for different pixel window widths. Figure $7 \mathrm{a}-\mathrm{c}$ show the validation results between the observed TSS and SASM-derived TSS for AVD30, AVD60 and AVD90 respectively. As the time difference between MODIS-Aqua overpass and in situ data collection increases the spatial variability in the SASM-derived TSS also increases, as indicated by the error bars displayed on each data point tending to lengthen as we move from AVD30 to AVD90. The effect of TSS spatial variability can be minimised by using an aggregate of larger pixel window sizes. However, using larger window width can also result in higher variability in TSS, especially in waters that vary rapidly in the spatial domain, a common characteristic of waters associated with dredging operations. For our study site, on the second field trip, we visually observed that high spatial variation in TSS was present in a small spatial domain.

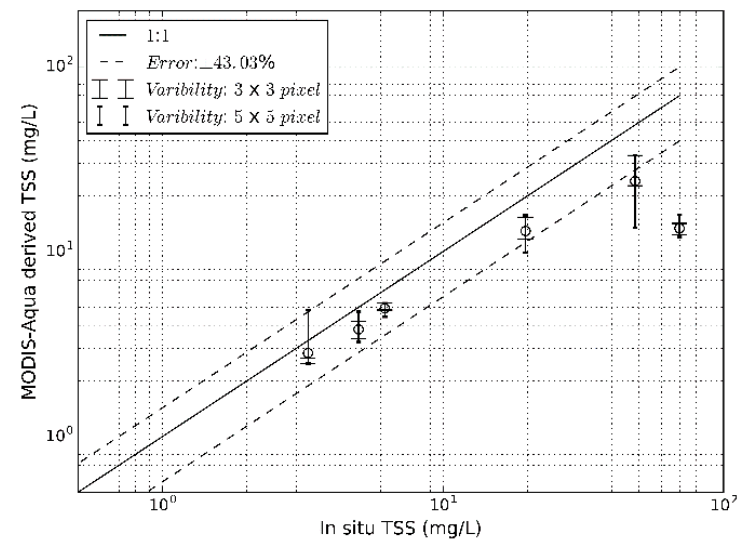

(a)

Figure 7. Cont. 


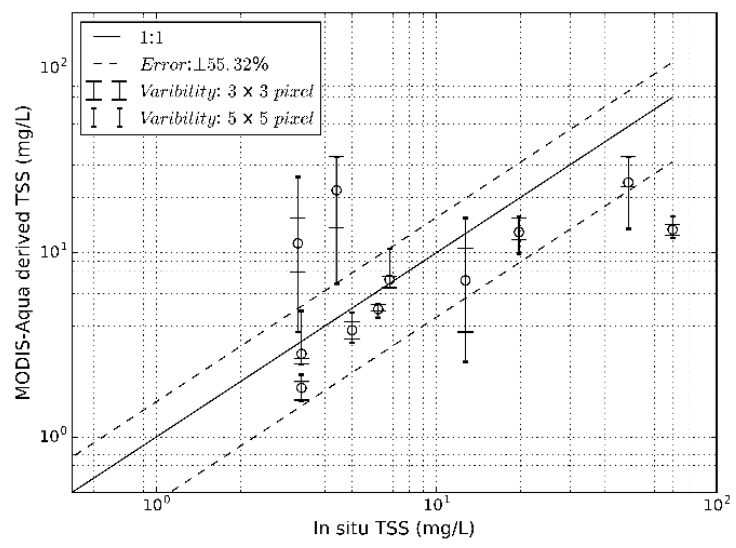

(b)

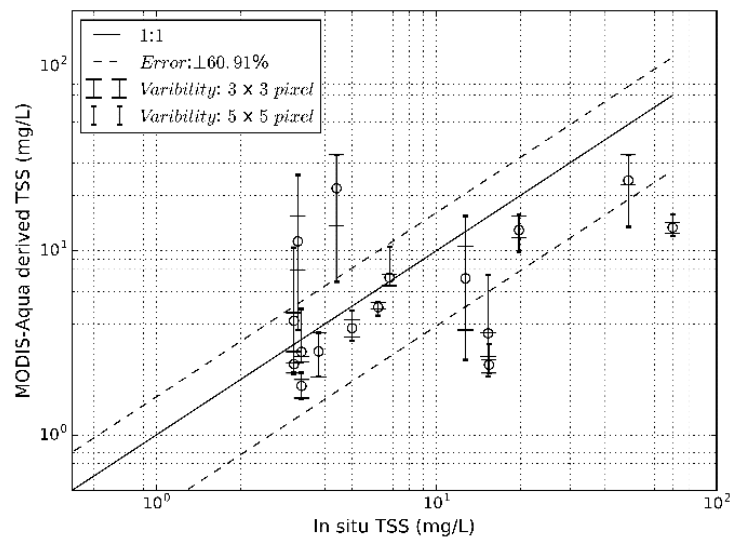

(c)

Figure 7. Validation between the SASM-derived TSS from MODIS-Aqua band 1 reflectance for (a) AVD30; (b) AVD60; and (c) AVD90. The error bar indicates the minimum and maximum TSS computed in $3 \times 3$ and $5 \times 5$-pixel window widths.

\subsubsection{Temporal Analysis of 2013 MODIS Imagery}

The daily and monthly TSS averages for SG, DA and CA were computed and are shown in Figure 8a,b respectively. In MODIS-Aqua daily TSS plots we see that SG and DA TSS are consistently higher than CA, which is expected because of the location of CA being further from the coast, further from the dredge operation, and in deeper waters thus have less re-suspension of TSS from local tidal influences. The monthly average of MODIS-Terra derived TSS in DA is higher than SG from the beginning of 2013 until June 2013 and then comparable to SG from July 2013 until the end of 2013. After June 2013, the MODIS-Aqua derived TSS in DA is slightly higher than SG for all months except July and October. However, the differences in monthly averaged TSS concentration between SG and DA after June 2013 are not different than monthly averaged TSS concentration before June 2013 (refer to Figure 8a,b for details). The apparent shift in TSS, in MODIS-Aqua data, from SG being lower in the early half of 2013 and increasing in the later part of 2013 may be as a result of the increasing load of spoil in the SG. Further, the effect of river outflow from the Ashburton River and intermediate streams created by heavy rain might be a cause of DA being higher in TSS when compared with SG during the early half of 2013. Rainfall data for Onslow Airport shows there was higher rainfall from January to June 2013 when compared with July to December [83]. 


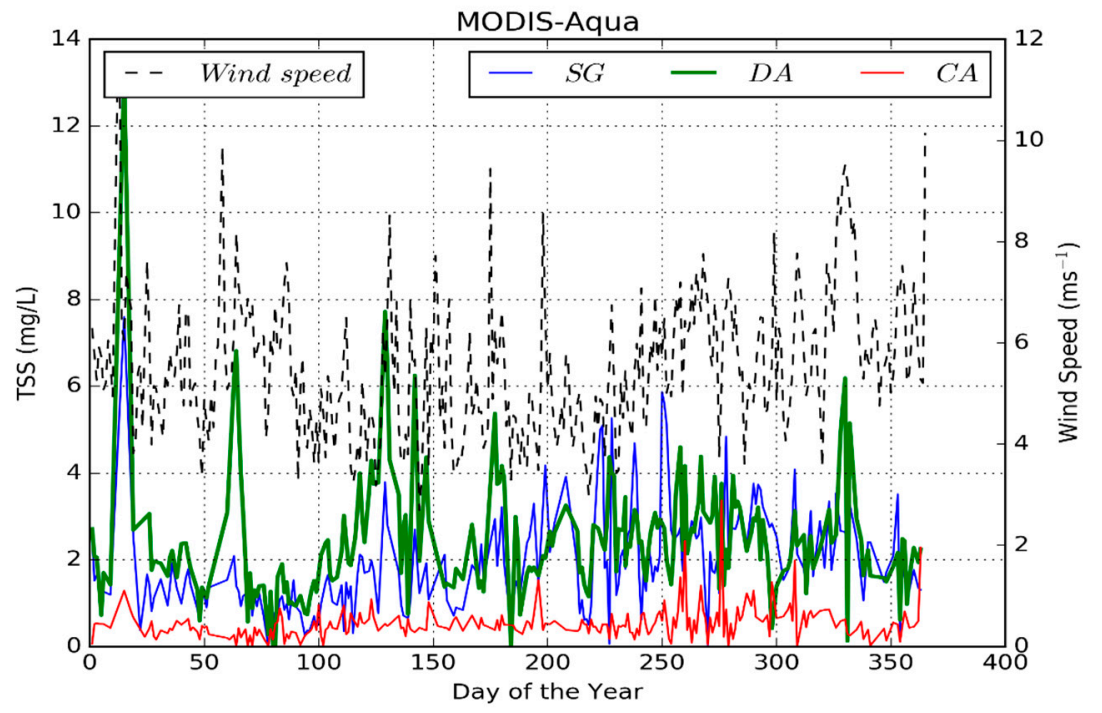

(a)

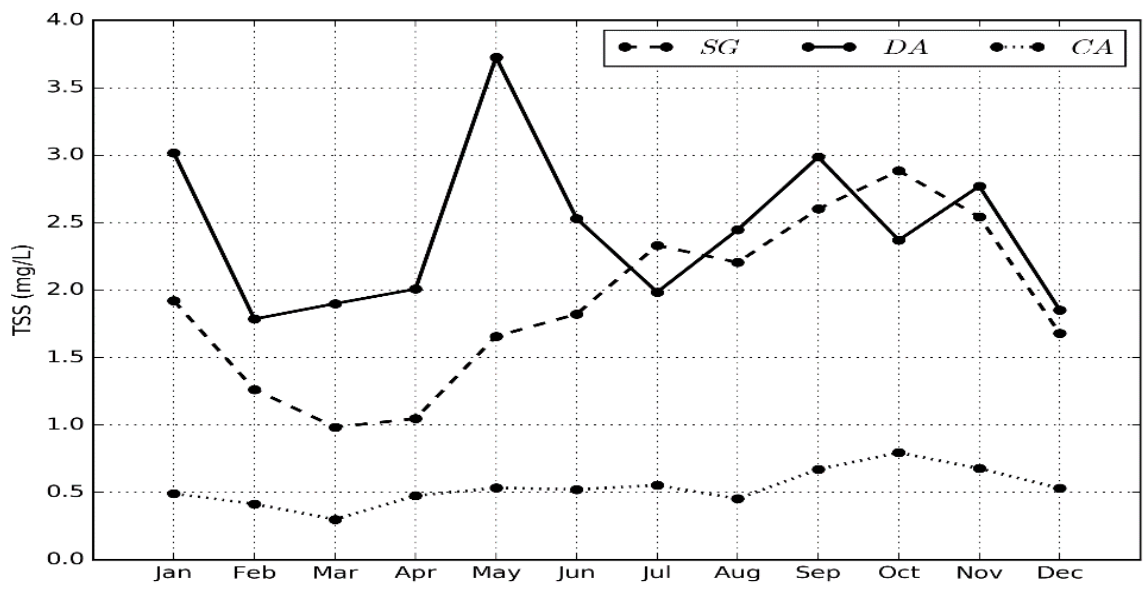

(b)

Figure 8. Daily (a) and monthly averaged (b) TSS derived from the SASM for 2013 MODIS-Aqua data.

Figure 8a shows a number of anomalies in daily TSS when compared with the respective trend, apparent as "spikes" in the data. Such anomalies were examined with respect to the wind speed of the study site to study the potential links to re-suspension of sediment in the water column. From the daily mean average wind speed in 2013 acquired from the Bureau of Meteorology (http:/ /www.bom.gov.au) for Onslow Airport, we performed a correlation analysis between wind speed on different days and TSS for all three study regions. In general, for wind speeds less than $7 \mathrm{~m} \cdot \mathrm{s}^{-1}$ there was no significant correlation between wind speed and TSS for any of the regions. For speeds greater than $8 \mathrm{~m} \cdot \mathrm{s}^{-1}$, and for two and three days before the TSS dates, there was strong correlation observed between TSS and wind speed at all three regions. The results show that for MODIS-Aqua derived TSS, a lag of three days gives the highest correlation $(r=0.92)$ for the DA. The correlation results between wind speed and TSS indicates that the re-suspension of sediments from wind speed greater than $8 \mathrm{~m} \cdot \mathrm{s}^{-1}$ tends to take about three days to build to a maximum before settling down. Specific TSS anomalies in the time series, such as those observed on days 15 (15 January) and 61 (2 March) in Figure 8a correspond to the effects of tropical cyclone Narelle which moved as close as $330 \mathrm{~km}$ off the coast of Exmouth on 12 January 2013 and severe tropical cyclone Rusty which made landfall on 27 February 2013 in Port Hedland which is located at $389 \mathrm{~km}$ north east of Onslow [84]. 
Figure 9 show a series of monthly average TSS images spanning 2013 derived from MODIS-Aqua using the SASM. January was impacted by tropical cyclone Narelle, which crossed the study site on 11 and 12 January 2013, thus the average TSS levels are relatively high and widespread. The monthly images show that TSS levels in the SG and DA begin to increase from May and maintain high levels until October, then tend to decrease during November and December. The increase in TSS in both the SG and DA from May is likely due to dredging activities being carried out starting in May and continuing until October 2013. The maximum monthly TSS averages were observed in October in the SG with a TSS concentration of $2.88 \pm 0.52 \mathrm{mg} / \mathrm{L}$, in the DA the maximum was $3.73 \pm 1.21 \mathrm{mg} / \mathrm{L}$ in May, and the CA displayed a maximum of $0.79 \pm 0.04 \mathrm{mg} / \mathrm{L}$ in October amongst the MODIS-Aqua derived monthly TSS averages. The monthly TSS averages were higher in SG and DA from May to December than the January to March, despite the higher rainfall in the first six months of 2013 [83]. This is a strong indication of the impact of the dredge process causing higher TSS concentrations.
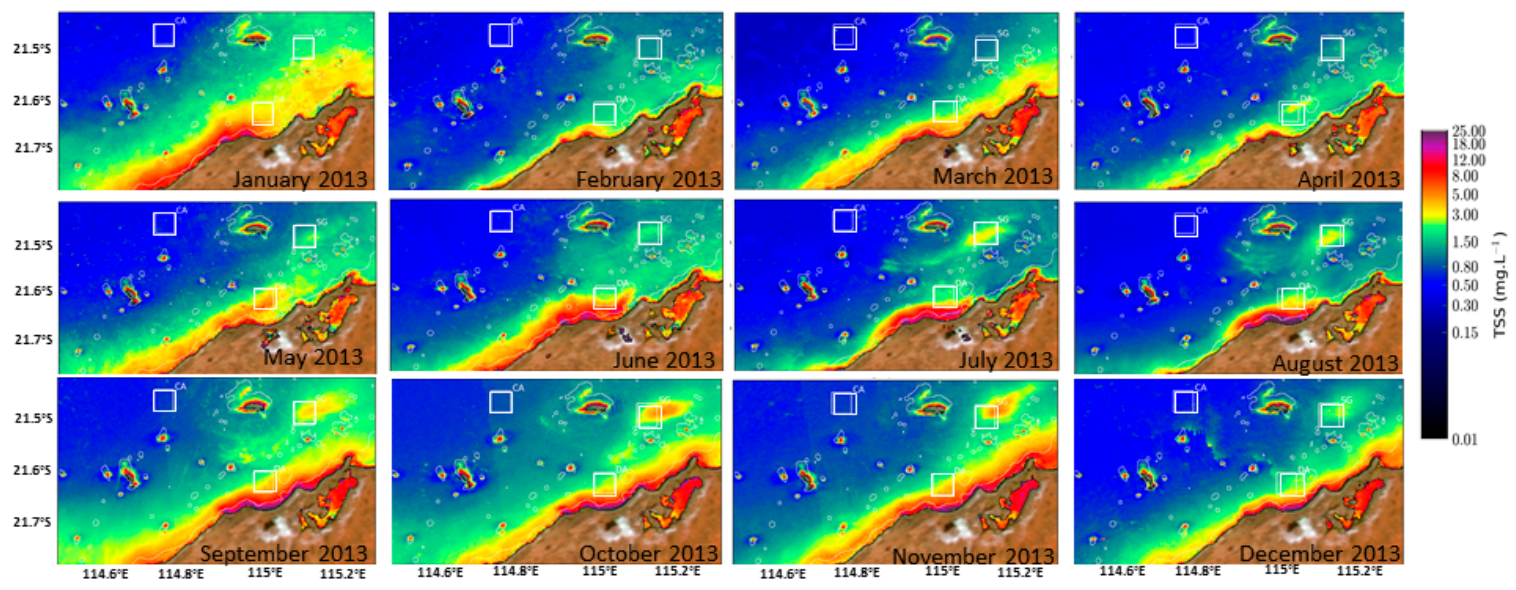

Figure 9. 2013 monthly averaged TSS images derived from MODIS-Aqua $250 \mathrm{~m}$ band 1 (January to December 2013). Rectangles represent locations for CA, DA, and SG.

\section{Conclusions}

In this paper we developed a semi-analytic sediment model (SASM) that is both physically sensible in its general form and adapted to the northern Western Australian coastal waters in retrieving TSS from $250 \mathrm{~m}$ MODIS-Aqua band 1 reflectance. We assessed the inherent uncertainty due to combined model and atmospheric correction effects in the retrieved TSS product to be $43.03 \%$ to $60.91 \%$ for MODIS-Aqua. We demonstrated the application of the SASM TSS concentration product in analysing MODIS-Aqua data for 2013 and associated this with the dredge activities at Onslow in Western Australia. The $250 \mathrm{~m}$ imagery was successful at highlighting the impact of cyclones and dredge activities on dredge spoil grounds and dredge operation areas. Further, daily anomalies in temporal data were able to be linked to specific causes, including dredge activities, cyclone events, wind-induced re-suspension, and increased river outflow. Thus, we have shown that the SASM, in conjunction with an appropriate atmospheric correction method for MODIS-Aqua band 1, should be sufficient for monitoring TSS in Onslow waters or waters with similar optical properties before, during and after dredging operations. The SASM developed in this study can be applied to other regional waters of Western Australia or waters with similar optical properties, but the application of the SASM beyond the regional waters of Western Australia should be carried out with recalibration of the SASM parameters. The merits of the SASM are the ease in calibration using in situ TSS concentration for particular regions of interest, akin to fully empirical algorithm, but also the robustness based on a physical foundation of the radiative transfer theory. 
Supplementary Materials: The following are available online at www.mdpi.com/2072-4292/8/7/556/s1, Figure S1: (a) Scatter plot for modelled and HydroLight $\omega_{b}^{\prime}(650 \mathrm{~nm})$; (b) $\omega_{b}^{\prime}(650 \mathrm{~nm})$ as a function of TSS, Figure S2: (a) Scatter plot for modelled and HydroLight $\omega_{b}^{\prime}(790 \mathrm{~nm}) ;(b) \omega_{b}^{\prime}(790 \mathrm{~nm})$ as a function of TSS, Table S1: Six different water types grouped based on CHL concentration and CDOM, Table S2: Comparative $\omega_{b}^{\prime}(494 \mathrm{~nm})$ results for the NRP and SASM models (all $p<0.005)$, Table S3: Comparative $\omega_{b}^{\prime}(566 \mathrm{~nm})$ results for the NRP and SASM models (all $p<0.005)$, Table S4: Comparative $\omega_{b}^{\prime}(650 \mathrm{~nm})$ results for the NRP and SASM models (all $p<0.005)$, Table S5: Comparative $(790 \mathrm{~nm})$ results for the NRP and SASM models (all $p<0.005)$.

Acknowledgments: This study was funded by Western Australian Marine Science Institution through Dredging Science Node project 2/3. The authors wish to acknowledge Curtin University for providing a postgraduate research scholarship to Passang Dorji. The authors also wish to acknowledge the logistical support from masters and crew of RV Linnaeus (CSIRO) and RV Solander (AIMS).

Author Contributions: The general conception of this study was developed by all three authors. Theoretical conception of the model was developed by Passang Dorji with guidance from Peter Fearns. Processing of in situ and satellite data was performed by Passang Dorji and Mark Broomhall with supervision from Peter Fearns. The interpretation of the data was performed by Passang Dorji with supervision of Peter Fearns. Passang Dorji wrote the manuscript, Peter Fearns and Mark Broomhall provided revision and critical feedback to the manuscript.

Conflicts of Interest: The authors declare no conflict of interest.

\section{Appendix A The optical depth for MODIS sensor band 1 simulated using HydroLight.}

To ascertain how far below the water's surface MODIS can "see" in MODIS band 1, we simulated diffuse attenuation coefficients $(\mathrm{Kd})$ for the near surface waters for different chlorophyll (CHL) and CDOM for a range of TSS concentrations using HydroLight 4.2 [44]. From the simulated Kd results, with the assumption that $90 \%$ of the diffuse light comes from a water column of depth of $1 / \mathrm{Kd}[85]$, MODIS band 1 can only penetrate $1.9 \mathrm{~m}$ at a TSS concentration of $3.9 \mathrm{mg} / \mathrm{L}$ for even very low CHL and CDOM. For high CHL and CDOM concentrations, the penetration depth of MODIS band 1 is only $1.5 \mathrm{~m}$ even for zero TSS. Thus, the TSS data collected from a depth of $\sim 1.9 \mathrm{~m}$ may be unsuitable for remotely sensed TSS algorithm development or validation.

\section{References}

1. Acker, J.G.; Harding, L.W.; Leptoukh, G.; Zhu, T.; Shen, S. Remotely-sensed chl a at the chesapeake bay mouth is correlated with annual freshwater flow to chesapeake bay. Geophys. Res. Lett. 2005, 32, L05601. [CrossRef]

2. Arrigo, K.R.; McClain, C.R. Spring phytoplankton production in western ross sea. Science 1994, 266, $261-263$. [CrossRef] [PubMed]

3. Jutla, A.S.; Akanda, A.S.; Islam, S. Satellite remote sensing of space-time plankton variability in the bay of bengal: Connections to cholera outbreaks. Remote Sens. Environ. 2012, 123, 196-206. [CrossRef] [PubMed]

4. Sullivan, C.W.; Arrigo, K.R.; McClain, C.R.; Comiso, J.C.; Firestone, J. Distribution of phytoplankton blooms in the southern ocean. Science 1993, 262, 1832-1837. [CrossRef] [PubMed]

5. Kutser, T.; Pierson, D.C.; Tranvik, L.; Reinart, A.; Sobek, S.; Kallio, K. Using satellite remote sensing to estimate the colored dissolved organic matter absorption coefficient in lakes. Ecosystems 2005, 8, 709-720. [CrossRef]

6. Loisel, H.; Vantrepotte, V.; Dessailly, D.; MÈriaux, X. Assessment of the colored dissolved organic matter in coastal waters from ocean color remote sensing. Opt. Express 2014, 22, 13109-13124. [CrossRef] [PubMed]

7. Tiwari, S.P.; Shanmugam, P. An optical model for the remote sensing of coloured dissolved organic matter in coastal/ocean waters. Estuar. Coast. Shelf Sci. 2011, 93, 396-402. [CrossRef]

8. Binding, C.E.; Bowers, D.G.; Mitchelson-Jacob, E.G. Estimating suspended sediment concentrations from ocean colour measurements in moderately turbid waters; the impact of variable particle scattering properties. Remote Sens. Environ. 2005, 94, 373-383. [CrossRef]

9. Chen, Z.; Hu, C.; Muller-Karger, F. Monitoring turbidity in tampa bay using MODIS/aqua 250-m imagery. Remote Sens. Environ. 2007, 109, 207-220. [CrossRef]

10. Martinez, J.M.; Guyot, J.L.; Filizola, N.; Sondag, F. Increase in suspended sediment discharge of the Amazon river assessed by monitoring network and satellite data. CATENA 2009, 79, 257-264. [CrossRef] 
11. Ayana, E.K.; Worqlul, A.W.; Steenhuis, T.S. Evaluation of stream water quality data generated from MODIS images in modeling total suspended solid emission to a freshwater lake. Sci. Total Environ. 2015, 523, 170-177. [CrossRef] [PubMed]

12. Park, E.; Latrubesse, E.M. Modeling suspended sediment distribution patterns of the Amazon river using MODIS data. Remote Sens. Environ. 2014, 147, 232-242. [CrossRef]

13. Doxaran, D.; Froidefond, J.-M.; Castaing, P. Remote-sensing reflectance of turbid sediment-dominated waters. Reduction of sediment type variations and changing illumination conditions effects by use of reflectance ratios. Appl. Opt. 2003, 42, 2623-2634. [CrossRef] [PubMed]

14. Vos, R.J.; Hakvoort, J.H.M.; Jordans, R.W.J.; Ibelings, B.W. Multiplatform optical monitoring of eutrophication in temporally and spatially variable lakes. Sci. Total Environ. 2003, 312, 221-243. [CrossRef]

15. Kallio, K.; Attila, J.; Härmä, P.; Koponen, S.; Pulliainen, J.; Hyytiäinen, U.M.; Pyhälahti, T. Landsat ETM+ images in the estimation of seasonal lake water quality in boreal river basins. Environ. Manag. 2008, 42, 511-522. [CrossRef] [PubMed]

16. Wu, G.; De Leeuw, J.; Skidmore, A.K.; Prins, H.H.T.; Liu, Y. Comparison of MODIS and Landsat TM5 images for mapping tempo-spatial dynamics of secchi disk depths in Poyang lake national nature reserve, China. Int. J. Remote Sens. 2008, 29, 2183-2198. [CrossRef]

17. Zhou, W.; Wang, S.; Zhou, Y.; Troy, A. Mapping the concentrations of total suspended matter in lake Taihu, China, using Landsat-5 TM data. Int. J. Remote Sens. 2006, 27, 1177-1191. [CrossRef]

18. Vanhellemont, Q.; Ruddick, K. Turbid wakes associated with offshore wind turbines observed with Landsat 8. Remote Sens. Environ. 2014, 145, 105-115. [CrossRef]

19. Wu, G.; Cui, L.; Liu, L.; Chen, F.; Fei, T.; Liu, Y. Statistical model development and estimation of suspended particulate matter concentrations with Landsat 8 OLI images of Dongting lake, China. Int. J. Remote Sens. 2015, 36, 343-360. [CrossRef]

20. Zhang, M.; Dong, Q.; Cui, T.; Xue, C.; Zhang, S. Suspended sediment monitoring and assessment for Yellow river estuary from Landsat TM and ETM + imagery. Remote Sens. Environ. 2014, 146, 136-147. [CrossRef]

21. Kratzer, S.; Brockmann, C.; Moore, G. Using MERIS full resolution data to monitor coastal waters-A case study from Himmerfjärden, a fjord-like bay in the northwestern Baltic sea. Remote Sens. Environ. 2008, 112, 2284-2300. [CrossRef]

22. Odermatt, D.; Heege, T.; Nieke, T.; Kneubuhler, M.; Itten, K.I. Water quality monitoring for lake constance with a physically based algorithm for MERIS data. Sensors 2008, 8, 4582-4599. [CrossRef]

23. Chen, X.; Han, X.; Feng, L. Towards a practical remote-sensing model of suspended sediment concentrations in turbid waters using MERIS measurements. Int. J. Remote Sens. 2015, 36, 3875-3889. [CrossRef]

24. Qing, S.; Zhang, J.; Cui, T.; Bao, Y. Remote sensing retrieval of inorganic suspended particle size in the Bohai sea. Cont. Shelf Res. 2014, 73, 64-71. [CrossRef]

25. Raag, L.; Uiboupin, R.; Sipelgas, L. In Analysis of historical MERIS and MODIS data to evaluate the impact of dredging to monthly mean surface tsm concentration. Proc. SPIE 2013. [CrossRef]

26. Tarrant, P.E.; Amacher, J.A.; Neuer, S. Assessing the potential of medium-resolution imaging spectrometer (MERIS) and moderate-resolution imaging spectroradiometer (MODIS) data for monitoring total suspended matter in small and intermediate sized lakes and reservoirs. Water Resour. Res. 2010. [CrossRef]

27. Miller, R.L.; McKee, B.A. Using MODIS terra $250 \mathrm{~m}$ imagery to map concentrations of total suspended matter in coastal waters. Remote Sens. Environ. 2004, 93, 259-266. [CrossRef]

28. Chen, S.; Han, L.; Chen, X.; Li, D.; Sun, L.; Li, Y. Estimating wide range total suspended solids concentrations from MODIS 250-m imageries: An improved method. ISPRS J. Photogramm. Remote Sens. 2015, 99, 58-69. [CrossRef]

29. Hudson, B.; Overeem, I.; McGrath, D.; Syvitski, J.P.M.; Mikkelsen, A.; Hasholt, B. MODIS observed increase in duration and spatial extent of sediment plumes in greenland Fjords. Cryosphere 2014, 8, 1161-1176. [CrossRef]

30. Petus, C.; Marieu, V.; Novoa, S.; Chust, G.; Bruneau, N.; Froidefond, J.-M. Monitoring spatio-temporal variability of the Adour river turbid plume (bay of Biscay, France) with MODIS 250-m imagery. Cont. Shelf Res. 2014, 74, 35-49. [CrossRef]

31. Doxaran, D.; Froidefond, J.M.; Lavender, S.; Castaing, P. Spectral signature of highly turbid waters: Application with SPOT data to quantify suspended particulate matter concentrations. Remote Sens. Environ. 2002, 81, 149-161. [CrossRef] 
32. Ekercin, S. Water quality retrievals from high resolution ikonos multispectral imagery: A case study in Istanbul, Turkey. Water Air Soil Pollut. 2007, 183, 239-251. [CrossRef]

33. Tyler, A.N.; Svab, E.; Preston, T.; Présing, M.; Kovács, W.A. Remote sensing of the water quality of shallow lakes: A mixture modelling approach to quantifying phytoplankton in water characterized by high-suspended sediment. Int. J. Remote Sens. 2006, 27, 1521-1537. [CrossRef]

34. Wang, F.; Zhou, B.; Xu, J.; Song, L.; Wang, X. Application of neural netword and MODIS $250 \mathrm{~m}$ imagery for estimating suspended sediments concentration in Hangzhou bay, China. Environ. Geol. 2008, 56, 1093-1101. [CrossRef]

35. Shi, K.; Zhang, Y.; Zhu, G.; Liu, X.; Zhou, Y.; Xu, H.; Qin, B.; Liu, G.; Li, Y. Long-term remote monitoring of total suspended matter concentration in lake Taihu using $250 \mathrm{~m}$ MODIS-aqua data. Remote Sens. Environ. 2015, 164, 43-56. [CrossRef]

36. Kaba, E.; Philpot, W.; Steenhuis, T. Evaluating suitability of MODIS-Terra images for reproducing historic sediment concentrations in water bodies: Lake Tana, Ethiopia. Int. J. Appl. Earth Obs. Geoinform. 2014, 26, 286-297. [CrossRef]

37. Choi, J.K.; Park, Y.J.; Lee, B.R.; Eom, J.; Moon, J.E.; Ryu, J.H. Application of the geostationary ocean color imager (GOCI) to mapping the temporal dynamics of coastal water turbidity. Remote Sens. Environ. 2014, 146, 24-35. [CrossRef]

38. Cui, L.; Qiu, Y.; Fei, T.; Liu, Y.; Wu, G. Using remotely sensed suspended sediment concentration variation to improve management of Poyang lake, China. Lake Reserv. Manag. 2013, 29, 47-60. [CrossRef]

39. Duan, H.; Ma, R.; Zhang, Y.; Zhang, B. Remote-sensing assessment of regional inland lake water clarity in northeast China. Limnology 2009, 10, 135-141. [CrossRef]

40. Shen, F.; Zhou, Y.; Peng, X.; Chen, Y. Satellite multi-sensor mapping of suspended particulate matter in turbid estuarine and coastal ocean, China. Int. J. Remote Sens. 2014, 35, 4173-4192. [CrossRef]

41. Qiu, Z. A simple optical model to estimate suspended particulate matter in Yellow river estuary. Opt. Express 2013, 21, 27891-27904. [CrossRef] [PubMed]

42. Espinoza Villar, R.; Martinez, J.-M.; Le Texier, M.; Guyot, J.-L.; Fraizy, P.; Meneses, P.R.; Oliveira, E.d. A study of sediment transport in the Madeira river, Brazil, using MODIS remote-sensing images. J. S. Am. Earth Sci. 2013, 44, 45-54. [CrossRef]

43. Petus, C.; Chust, G.; Gohin, F.; Doxaran, D.; Froidefond, J.-M.; Sagarminaga, Y. Estimating turbidity and total suspended matter in the adour river plume (south bay of Biscay) using MODIS 250-m imagery. Cont. Shelf Res. 2010, 30, 379-392. [CrossRef]

44. Mobley, C.D. Light and Water: Radiative Transfer in Natural Waters; Academic Press: San Diego, CA, USA, 1994.

45. Doxaran, D.; Castaing, P.; Lavender, S.J. Monitoring the maximum turbidity zone and detecting fine-scale turbidity features in the gironde estuary using high spatial resolution satellite sensor (SPOT HRV, Landsat $\mathrm{ETM}+$ ) data. Int. J.Remote Sens. 2006, 27, 2303-2321. [CrossRef]

46. Alikas, K.; Reinart, A. Validation of the MERIS products on large European lakes: Peipsi, Vänern and Vättern. Hydrobiologia 2008, 599, 161-168. [CrossRef]

47. Kutser, T.; Metsamaa, L.; Vahtmae, E.; Aps, R. Operative monitoring of the extent of dredging plumes in coastal ecosystems using MODIS satellite imagery. J. Coast. Res. 2007, 50, 180-184.

48. Sipelgas, L.; Raudsepp, U.; Kõuts, T. Operational monitoring of suspended matter distribution using MODIS images and numerical modelling. Adv. Space Res. 2006, 38, 2182-2188. [CrossRef]

49. Sokoletsky, L.; Yang, X.; Shen, F. MODIS-based Retrieval of suspended sediment concentration and diffuse attenuation coefficient in Chinese estuarine and coastal waters. Proc. SPIE 2014. [CrossRef]

50. Hu, C.; Chen, Z.; Clayton, T.D.; Swarzenski, P.; Brock, J.C.; Muller-Karger, F.E. Assessment of estuarine water-quality indicators using MODIS medium-resolution bands: Initial results from tampa bay, FL. Remote Sens. Environ. 2004, 93, 423-441. [CrossRef]

51. Zhang, M.; Tang, J.; Dong, Q.; Song, Q.; Ding, J. Retrieval of total suspended matter concentration in the yellow and east china seas from MODIS imagery. Remote Sensi. Environ. 2010, 114, 392-403. [CrossRef]

52. Li, J.; Gao, S.; Wang, Y. Delineating suspended sediment concentration patterns in surface waters of the Changjiang estuary by remote sensing analysis. Acta Oceanol. Sin. 2010, 29, 38-47. [CrossRef]

53. Tang, S.; Larouche, P.; Niemi, A.; Michel, C. Regional algorithms for remote-sensing estimates of total suspended matter in the Beaufort sea. Int. J. Remote Sens. 2013, 34, 6562-6576. [CrossRef] 
54. Chen, J.; D'Sa, E.; Cui, T.; Zhang, X. A semi-analytical total suspended sediment retrieval model in turbid coastal waters: A case study in Changiiang river estuary. Opt. Express 2013, 21, 13018-13031. [CrossRef] [PubMed]

55. Brando, V.E.; Dekker, A.G. Satellite hyperspectral remote sensing for estimating estuarine and coastal water quality. IEEE Trans. Geosci. Remote Sens. 2003, 41, 1378-1387. [CrossRef]

56. Chen, S.; Zhang, T.; Hu, L. Evaluation of the NIR-SWIR atmospheric correction algorithm for MODIS-aqua over the eastern China seas. Int. J. Remote Sens. 2014, 35, 4239-4251. [CrossRef]

57. Dekker, A.G.; Vos, R.J.; Peters, S.W.M. Analytical algorithms for lake water TSM estimation for retrospective analyses of TM and SPOT sensor data. Int. J. Remote Sens. 2002, 23, 15-35. [CrossRef]

58. Yang, W.; Matsushita, B.; Chen, J.; Fukushima, T. Estimating constituent concentrations in case II waters from MERIS satellite data by semi-analytical model optimizing and look-up tables. Remote Sens. Environ. 2011, 115, 1247-1259. [CrossRef]

59. Lee, Z.P.; Carder, K.L.; Mobley, C.D.; Steward, R.G.; Patch, J.S. Hyperspectral remote sensing for shallow waters: 2. Deriving bottom depths and water properties by optimization. Appl. Opt. 1999, 38. [CrossRef]

60. Nechad, B.; Ruddick, K.G.; Park, Y. Calibration and validation of a generic multisensor algorithm for mapping of total suspended matter in turbid waters. Remote Sens. Environ. 2010, 114, 854-866. [CrossRef]

61. Kong, J.L.; Sun, X.M.; Wong, D.; Chen, Y.; Yang, J.; Yan, Y.; Wang, L.-X. A semi-analytical model for remote sensing retrieval of suspended sediment concentration in the gulf of Bohai, China. Remote Sens. 2015, 7, 5373. [CrossRef]

62. Wang, P.; Boss, E.S.; Roesler, C. Uncertainties of inherent optical properties obtained from semianalytical inversions of ocean color. Appl. Opt. 2005, 44, 4074-4085. [CrossRef] [PubMed]

63. Bureau of Meteorology. Climate Statistics for Australian Location. Available online: http://www.bom.gov. $\mathrm{au} /$ climate/averages/tables/cw_005094.shtml (accessed on 4 November 2015).

64. WAPC. Onslow Regional Hotspot Land Supply Update; Planning Commission: Perth, Australia, 2011.

65. Chevron. Dredging and Dredge Spil Placement Environmental Monitoring and Management Plan; WSO-000HES-RPT-CVX-000-00086-000; Chevron Australia Pty Ltd.: Perth, Austrilia, 2014.

66. Brando, V.; Lovell, J.; King, E.; Boadle, D.; Scott, R.; Schroeder, T. The potential of autonomous ship-borne hyperspectral radiometers for the validation of ocean color radiometry data. Remote Sens. 2016, 8, 150. [CrossRef]

67. Mobley, C.D. Estimation of the remote-sensing reflectance from above-surface measurements. Appl. Opt. 1999, 38, 7442-7455. [CrossRef] [PubMed]

68. Feldman, G.C.; McClain, C.R. L2gen, Ocean Color Seadas. Available online: http:/ /seadas,gsfc.nasa.gov/ doc/12gen/12gen.html (accessed on 6 November 2015).

69. Wang, M. Remote sensing of the ocean contributions from ultraviolet to near-infrared using the shortwave infrared bands: Simulations. Appl. Opt. 2007, 46, 1535-1547. [CrossRef]

70. Ruddick, K.G.; Ovidio, F.; Rijkeboer, M. Atmospheric correction of seawifs imagery for turbid coastal and inland waters. Appl. Opt. 2000, 39, 897-912. [CrossRef] [PubMed]

71. Ody, A.; Doxaran, D.; Vanhellemont, Q.; Nechad, B.; Novoa, S.; Many, G.; Bourrin, F.; Verney, R.; Pairaud, I.; Gentili, B. Potential of high spatial and temporal ocean color satellite data to study the dynamics of suspended particles in a micro-tidal river plume. Remote Sens. 2016, 8, 245. [CrossRef]

72. Wang, M.; Son, S.; Shi, W. Evaluation of MODIS SWIR and NIR-SWIR atmospheric correction algorithms using seabass data. Remote Sens. Environ. 2009, 113, 635-644. [CrossRef]

73. Lee, Z.; Carder, K.L.; Arnone, R.A. Deriving inherent optical properties from water color: A multiband quasi-analytical algorithm for optically deep waters. Appl. Opt. 2002, 41, 5755-5772. [CrossRef] [PubMed]

74. Gordon, H.R.; Brown, O.B.; Evans, R.H.; Brown, J.W.; Smith, R.C.; Baker, K.S.; Clark, D.K. A semianalytic radiance model of ocean color. J. Geophys. Res. Atmos. 1988, 93, 10909-10924. [CrossRef]

75. Tiwari, S.P.; Shanmugam, P. An optical model for deriving the spectral particulate backscattering coefficients in oceanic waters. Ocean. Sci. 2013, 9, 987-1001. [CrossRef]

76. Moore, T.S., II; Matear, R.J.; Marra, J.; Clementson, L. Phytoplankton variability off the western australian coast: Mesoscale eddies and their role in cross-shelf exchange. Deep Sea Research Part II: Top. Stud. Oceanogr. 2007, 54, 943-960. [CrossRef] 
77. Babin, M.; Morel, A.; Fournier-Sicre, V.; Fell, F.; Stramski, D. Light scattering properties of marine particles in coastal and open ocean waters as related to the particle mass concentration. Limnol. Oceanogr. 2003, 48, 843-859. [CrossRef]

78. Babin, M.; Stramski, D.; Ferrari, G.M.; Claustre, H.; Bricaud, A.; Obolensky, G.; Hoepffner, N. Variations in the light absorption coefficient of phytoplankton, nonagal particles, and dissolved organic matter in coastal waters around europe. J. Geophys. Res. 2003, 108, 3211. [CrossRef]

79. Matthews, W.M. A current review of empirical procedures of remote sensing in inland and near-coastal transitional waters. Int. J. Remote Sens. 2011, 32, 6855-6899. [CrossRef]

80. Stone, M. Cross-validatory choice and assessment of statistical predictions. J. R. Stat. Soc. Ser. B Methodol. 1974, 36, 111-147.

81. Volpe, V.; Silvestri, S.; Marani, M. Remote sensing retrieval of suspended sediment concentration in shallow waters. Remote Sens. Environ. 2011, 115, 44-54. [CrossRef]

82. Efron, B. Bootstrap methods: Another look at the jackknife. Ann. Stat. 1979, 7, 1-26. [CrossRef]

83. Bureau of Meteorology. Daily Rainfall. Available online: http://www.bom.gov.au/jsp/ncc/cdio/ weatherData/av?p_nccObsCode $=136 \& p \_d i s p l a y \_t y p e=$ dailyDataFile $\&$ p_startYear $=2013 \&$ p_c $=-5258470 \&$ p_stn_num=005017 (accessed on 15 October 2015).

84. Bureau of Meteorology. Severe Tropical Cyclone Rusty. Available online: http://www.bom.gov.au/ announcements/sevwx/wa/watc20130222.shtml (accessed on 5 October 2015).

85. Mishra, D.R.; Narumalani, S.; Rundquist, D.; Lawson, M. Characterizing the vertical diffuse attenuation coefficient for downwelling irradiance in coastal waters: Implications for water penetration by high resolution satellite data. ISPRS J. Photogramm. Remote Sens. 2005, 60, 48-64. [CrossRef]

(C) 2016 by the authors; licensee MDPI, Basel, Switzerland. This article is an open access article distributed under the terms and conditions of the Creative Commons Attribution (CC-BY) license (http:/ / creativecommons.org/licenses/by/4.0/). 